\title{
Dust radiative effects on atmospheric thermodynamics and tropical cyclogenesis over the Atlantic Ocean using WRF-Chem coupled with an AOD data assimilation system
}

\author{
Dan Chen $^{1,2}$, Zhiquan Liu ${ }^{1}$, Chris Davis ${ }^{1}$, and Yu Gu ${ }^{3}$ \\ ${ }^{1}$ Mesoscale \& Microscale Meteorology Laboratory, National Center for Atmospheric Research, \\ Boulder, Colorado 80301, USA \\ ${ }^{2}$ Institute of Urban Meteorology, China Meteorological Administration, Beijing 100089, China \\ ${ }^{3}$ Department of Atmospheric and Oceanic Sciences, Joint Institute for Regional Earth System Science and Engineering, \\ University of California, Los Angeles, Los Angeles, California 90095, USA
}

Correspondence to: Zhiquan Liu (liuz@ucar.edu) and Dan Chen (dchen@ucar.edu)

Received: 19 August 2016 - Discussion started: 11 October 2016

Revised: 23 May 2017 - Accepted: 1 June 2017 - Published: 30 June 2017

\begin{abstract}
This study investigated the dust radiative effects on atmospheric thermodynamics and tropical cyclogenesis over the Atlantic Ocean using the Weather Research and Forecasting Model with Chemistry (WRF-Chem) coupled with an aerosol data assimilation (DA) system. MODIS AOD (aerosol optical depth) data were assimilated with the Gridpoint Statistical Interpolation (GSI) three-dimensional variational (3DVAR) DA scheme to depict the Saharan dust outbreak events in the 2006 summer. Comparisons with Ozone Monitoring Instrument (OMI), AErosol RObotic NETwork (AERONET), and Cloud-Aerosol Lidar and Infrared Pathfinder Satellite Observation (CALIPSO) observations showed that the system was capable of reproducing the dust distribution. Two sets of $180 \mathrm{~h}$ forecasts were conducted with the dust radiative effects activated (RE_ON) and inactivated (RE_OFF) respectively. Differences between the RE_ON and RE_OFF forecasts showed that low-altitude (high-altitude) dust inhibits (favors) convection owing to changes in convective inhibition (CIN). Heating in dust layers immediately above the boundary layer increases inhibition, whereas sufficiently elevated heating allows cooling above the boundary layer that reduces convective inhibition. Semi-direct effects in which clouds are altered by thermodynamic changes are also noted, which then alter cloudradiative temperature $(T)$ changes. The analysis of a tropical cyclone (TC) suppression case on 5 September shows evidence of enhanced convective inhibition by direct heating in
\end{abstract}

dust, but it also suggests that the low-predictability dynamics of moist convection reduces the determinism of the effects of dust on timescales of TC development (days).

\section{Introduction}

Mineral dust, one of the most abundant aerosol species in the atmosphere, has important weather and climatic effects through its influence on solar and terrestrial radiation and the radiative and physical properties of clouds (e.g., Grassl, 1975; Sokolik et al., 1998; Quijano et al., 2000; Ginoux et al., 2001; Ramanathan et al., 2001; Lau et al., 2009; Zhao et al., 2010). The Sahara desert over North Africa is the largest source of mineral dust in the world. During the summer months, the Saharan dust outbreaks are associated with a dry and hot well-mixed layer (Saharan air layer, SAL) extending to $\sim 500 \mathrm{hPa}$ over the North Atlantic Ocean. Saharan dust, often propagating downstream along the SAL to the Atlantic Ocean, can modify the SAL and its environment by changing the energy budget (e.g., Su et al., 2008; Chen et al., 2010; Zhao et al., 2010) through either scattering and absorption of sunlight (direct effect, e.g., Carlson and Benjamin, 1980; Zhu et al., 2007; Rosenfeld et al., 2008; Wong et al., 2009; Chen et al., 2010), thermodynamic effect on clouds (semi-direct, e.g., Hansen et al., 1997), or altering of cloud microphysical processes (indirect effects, e.g., Kaufman and Koren, 2006). 
As pollution and smoke aerosols can increase or decrease the cloud cover, this duality in the effects of aerosols forms one of the largest uncertainties in climate research (Koren et al., 2005, 2008; Kaufman and Koren, 2006). The term "semi-direct effect" was originally introduced by Hansen et al. (1997) to describe the impact of absorbing aerosols that cause cloud evaporation and thus dissipate the cloud prematurely. Modeling (Lohmann and Feichter, 2001; Cook and Highwood, 2004) and observational studies (Ackerman et al., 2000) showed that when aerosols are embedded within clouds, increased shortwave (SW) absorption could reduce relative humidity $(\mathrm{RH})$ and subsequently change cloud cover, e.g., decrease cloud cover especially at the upper level. However, the semi-direct effect of dust is sensitive to the position of the dust layer relative to clouds (Choobari et al., 2014). If the dust layer is located below clouds, heating within the dust layer can enhance convection and thus cloud cover. Absorbing aerosol above the cloud top may inhibit the vertical development of clouds and enhance the horizontal development by the suppression of entrainment due to the increase in temperature $(T)$ above the cloud (Johnson et al., 2004; Koch and Del Genio, 2010). All these lead to either a positive or negative radiative forcing associated with the semi-direct effect (Gu et al., 2010, 2016), which is poorly understood for Saharan dust.

Tropical cyclones (TCs) in the Atlantic basin often develop from mesoscale convective systems (MCSs) embedded within African easterly waves that originate over West Africa (Landsea, 1993). Whether easterly waves spawn tropical cyclones depends on the maintenance of a mesoscale region of rotation with deep moisture and a minimum of convective inhibition (CIN). Dust-induced thermodynamic changes, distinguished from indirect cloud effects, may modulate the environment of convection, thereby altering its frequency and other properties. Such direct and semi-direct effects can, in principle, alter the behavior of tropical disturbances. Several observational and numerical studies (e.g., Karyampudi and Carlson, 1988; Karyampudi and Pierce, 2002; Dunion and Velden, 2004; Evan et al., 2006; Jones et al., 2007; Wu, 2007; Sun et al., 2008, 2009; Pratt and Evans, 2009; Reale et al., 2009, 2014; Shu and Wu, 2009; Chen et al., 2010) have shown evidence for aerosol-induced intensification or weakening of TC development. For example, by using satellite data, Dunion and Velden (2004) have found that the dry SAL can suppress Atlantic TC activity by increasing the vertical wind shear and stabilizing the environment at low atmospheric levels. They also suggested that convectively driven downdrafts caused by the SAL dry air can be an important inhibiting factor for TCs. Based on a single case on 5-12 September 2006, Sun et al. (2009) also found that with the temperature and humidity assimilation of AIRS observations during dust outbreak periods the dry and warm SAL was better simulated such that the development of tropical disturbances was inhibited along the southern edge of the SAL due to enhanced downdrafts. By conducting a com- posite study of 274 cases using AIRS relative humidity, Shu and $\mathrm{Wu}$ (2009) provided evidence that the SAL can affect tropical cyclone intensity in both favorable (in the initial development) and unfavorable (subsequent development) manners. Bretl et al. (2015) confirmed the complexity of dust radiative effects by analyzing differences in hurricane genesis and frequency with radiatively active and inactive dust in the aerosol-climate model ECHAM6-HAM. These studies indicated that the Saharan dust could indeed influence Atlantic TC genesis, while the relationship and mechanisms are not fully understood. Most recent studies (e.g., Jenkins et al., 2008; Zhang et al., 2009; Hazra et al., 2013; Wang et al., 2014) aimed to reveal the coupled results of microphysical and radiative effects or to emphasize the microphysical impacts of dust on TCs - seeding hurricanes with dust acting as $\mathrm{CCN}$ (cloud condensation nuclei). Fewer papers focus solely on radiative effects, and there is still no consensus on whether the radiative effects of dust inhibit or favor TC development.

The magnitude of the radiative impact of dust highly depends upon the distribution of the dust concentration and its optical characteristics. While the modeling of the spatial distribution of the Saharan dust outbreak and its optical depth remains uncertain and challenging, AOD (aerosol optical depth) data assimilation (DA), combining satellitederived AOD observations with numerical model output, has proved to be skillful at improving aerosol and AOD forecasts (Collins et al., 2001; Liu et al., 2011). Liu et al. (2011, hereafter L11) implemented AOD DA within the National Centers for Environmental Prediction (NCEP) Gridpoint Statistical Interpolation (GSI) three-dimensional variational (3DVAR) DA system coupled to the Goddard Chemistry Aerosol Radiation and Transport (GOCART; Chin et al., 2000, 2002) aerosol scheme within the Weather Research and Forecasting Model with Chemistry (WRF-Chem; Grell et al., 2005). Verification results demonstrated improved aerosol forecasts from AOD DA over a week-long period in a study of a dust storm event over East Asia. Reale et al. (2014) used the NASA GEOS-5 global data assimilation and forecast system to investigate the aerosol direct radiative effects and their impact on the atmospheric dynamics. The improved aerosol and meteorological analysis fields by assimilating MODIS AOD, satellite, and conventional data sets were used to initialize the forecast by GEOS-5. Reale et al. (2014) did two sets of simulations (with dust radiatively active and inactive) for the period of 15 August-17 September 2006. The differences between the two runs revealed the dust suppression effect on Atlantic tropical cyclones - strong dust effects make the environment less conducive to tropical cyclone development.

In this study, we will further extend our previous air quality-oriented study (Chen et al., 2014; Schwartz et al., 2014) to investigate the dust radiation effects on thermodynamics and TC genesis in the Atlantic Ocean using the GSI-WRF-Chem coupled AOD DA system. Model description and experimental design are presented in Sect. 2. In 
Sect. 3, we investigated the dust radiative effects on atmospheric thermodynamics emphasizing temperature and convective inhibition energy changes caused by dust at different altitudes. Then we examined the hypothesis that the dust at different altitudes induced different temperature and CIN changes above the top of the boundary layer, which in turn may modulate the frequency and strength of the TC genesis in either a favorable or unfavorable manner. Statistics based on the summer of 2006 and case analysis were both provided. Conclusions are given in Sect. 4.

\section{Model description and experimental design}

Version 3.4.1 of WRF-Chem was employed with "online" coupled meteorological and chemical processes. The model domain with $36 \mathrm{~km}$ horizontal grid spacing covers the Atlantic Ocean and the Sahara desert (see Fig. 2). There are 57 vertical levels extending from the surface to $10 \mathrm{hPa}$. Aerosol direct and semi-direct effects are allowed in WRFChem by linking the optical properties of GOCART aerosols ( $\mathrm{OC}$ and $\mathrm{BC}$ with two size bins, sulfate and dust with five size bins, and sea salt with four size bins) to the Goddard Space Flight Center shortwave radiation scheme (Chou and Suarez, 1994). The scattering and absorption coefficients and single-scattering albedos are calculated by the "aerosol chemical to aerosol optical properties" module built in WRFChem (Barnard et al., 2010). The dust refractive indexes are wavelength dependent. An average single-scattering albedo of $\sim 0.9$ at $600 \mathrm{~nm}$ is reported by Zhao et al. (2010). Aerosol radiative effects on longwave (LW) radiation and aerosol indirect effects (i.e., aerosols as cloud condensation nuclei or ice nuclei in microphysics scheme) were not implemented for GOCART with the WRF-Chem version used. The WRF single-moment 6-class microphysics scheme and the GrellDevenyi ensemble cumulus parameterization (Grell and Devenyi, 2002) were used. The dust emission flux is computed as a function of the probability source function and surface wind speed (Ginoux et al., 2001). Similar to dust uplifting, sea salt emissions from the ocean are highly dependent on the surface wind speed and calculated as a function of wind speed at $10 \mathrm{~m}$ and sea salt particle radius (Chin et al., 2002). The lateral boundary conditions (LBCs) for meteorological fields were provided by the NCEP GFS (Global Forecast System) forecasts. LBCs for chemistry-aerosol fields were idealized profiles embedded within the WRF-Chem model.

NCEP's GSI 3DVAR DA system was used to assimilate the total $550 \mathrm{~nm}$ AOD (hereafter "AOD") retrievals (Collection 5) from MODIS sensors onboard the Terra and Aqua satellites, as described in L11. Retrievals of Deep Blue products over desert (Hsu et al., 2004) and dark targeting products over ocean and vegetated land (Remer et al., 2005) were assimilated in this study. Only AOD retrievals marked with the best quality flag were assimilated (see L11 for more detail). Several analyses of the Collection 5 MODIS over-ocean
AOD product show that MODIS AOD data accuracies are statistically comparable with other standard aerosol satellite products and can be used in operational aerosol assimilations (Yang et al., 2011; Ahn et al., 2014). L11 implemented AOD DA by using the Collection 5 MODIS $550 \mathrm{~nm}$ AOD data for studying a dust storm in East Asia, and verification results demonstrated improved aerosol forecasts from AOD DA over a week-long period. More results from our DA simulations, comparing with OMI (Ozone Monitoring Instrument) and AERONET (AErosol RObotic NETwork), are given in Sect. 3.

The GSI 3DVAR system calculates a best-fit "analysis" considering the observations (AOD in our case) and background fields (a short-term WRF-Chem forecast in our case) weighted by their error characteristics. The Community Radiative Transfer Model (Han et al., 2006; Liu and Weng, 2006) is used as the AOD observation operator in GSI to transform the GOCART aerosol profiles into AOD. Each aerosol species in 3-D is used as an analysis variable of 3DVAR, and the 3-D mass concentrations of the aerosol species are analyzed in a one-step minimization procedure constrained by the observation and background error covariances. The AOD observation error is assumed to be spatially uncorrelated and modeled in the same way as that in L11. To more accurately reflect the dust-dominated feature, the background error covariance statistics for each aerosol variable were calculated by utilizing the "NMC method" (National Meteorological Center method; Parrish and Derber, 1992) based upon the 1-month WRF-Chem forecasts for the dust outbreak month of August 2005. Standard deviations and horizontal and vertical correlation length scales of the background errors (separated for each aerosol species) were calculated using the method described by Wu et al. (2002). Note that only column-total $550 \mathrm{~nm}$ AOD was assimilated and no aerosol speciation information was contained in the observations. It is important to have the phenomena-specific background error statistics to allow for an appropriate adjustment of individual species. As a function of vertical model level, the domain-averaged standard deviations of the background errors for each GOCART aerosol species are shown in Fig. 1. Consistent with the dust outbreak period, the standard deviations of dust errors are 1 or 2 orders of magnitude larger than those of other species. A larger background error of dust allowed a larger adjustment of the dust field, which is crucial for the aerosol analyses of the Sahara dust outbreak period in this study. Further details for the AOD DA system, including the algorithm, the observation operator, and the modeling of the background and observation error covariances, can be found in L11.

We selected the 2006 summer, which has been investigated for similar interests in several studies as aforementioned (Sun et al., 2009; Reale et al., 2014). The MODIS AOD assimilation experiment was conducted using this GSIWRF-Chem coupled system. The experiment initialized a $6 \mathrm{~h}$ WRF-Chem forecast every $6 \mathrm{~h}$ starting from 00:00 UTC 

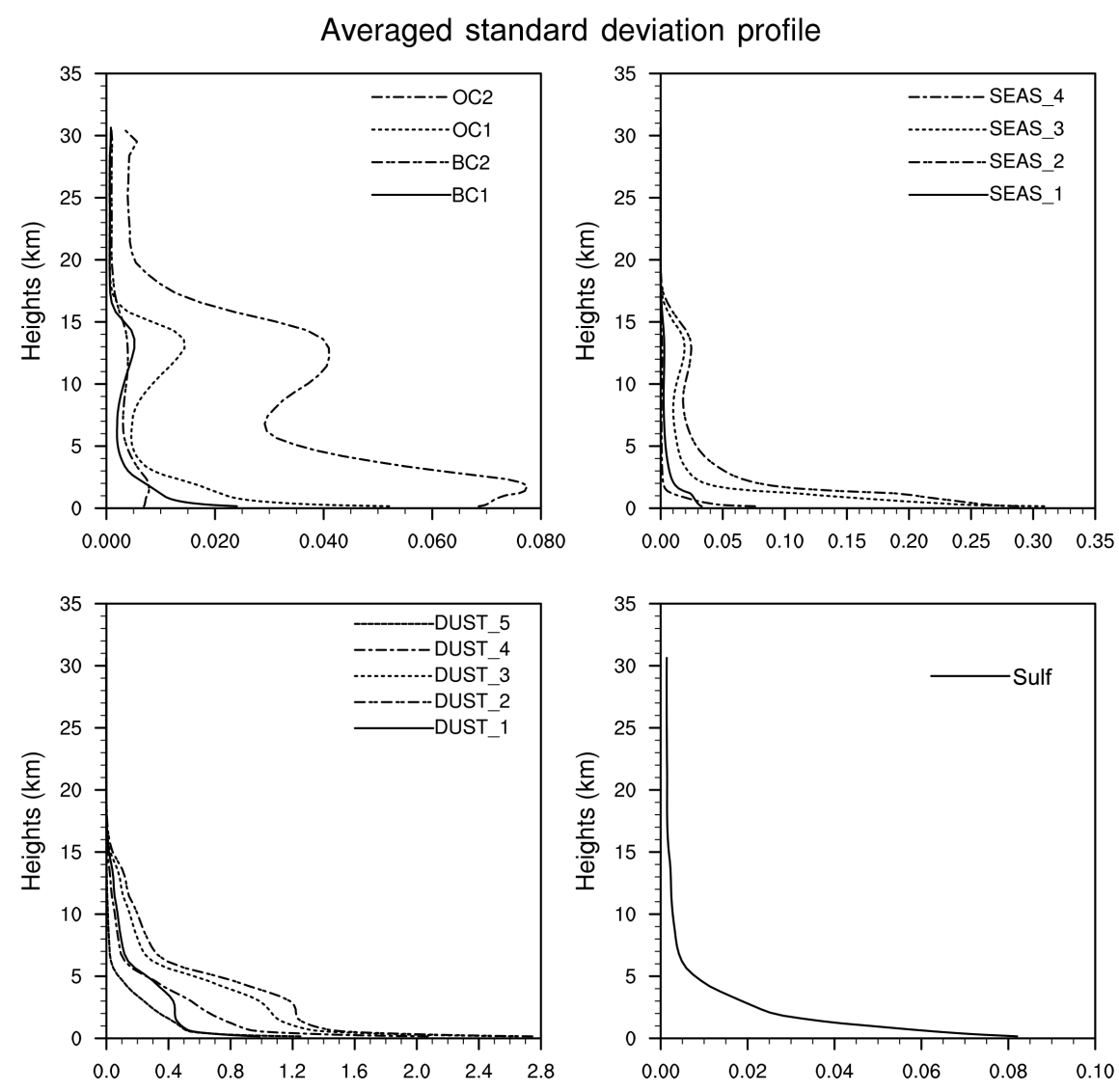

Figure 1. Domain-averaged standard deviations of background errors $\left(\mu \mathrm{g} \mathrm{kg}^{-1}\right)$ as a function of height for each aerosol variable.

on 1 July to 00:00 UTC on 18 September 2006. In this period, several TC genesis cases occurred along with the outbreaks of the Saharan dust. The 1 st week of simulation is taken as spin-up time, and the results from a later period (8 July-18 September) were analyzed. Meteorological initial condition (IC) for each forecast came from the GFS analysis (i.e., no regional meteorological DA). GSI 3DVAR updated GOCART aerosol variables by assimilating MODIS AOD at 12:00 and 18:00 UTC (when AOD observations were available) and using the previous cycle's $6 \mathrm{~h}$ forecast as the background. Two sets of $180 \mathrm{~h}$ forecasts were made at 00:00 UTC of each day (8 July-18 September) from this 6-hourly cycling procedure. The only difference between the two sets of forecasts is whether the aerosol radiative feedback is activated (RE_ON) or not (RE_OFF). Note that meteorological ICs in the two $180 \mathrm{~h}$ forecasts are the same (from the GFS analysis) and the forecast differences of meteorological fields between the RE_ON and RE_OFF experiments result solely from the differences in aerosol radiative effects.

It should be noted that in this study, the microphysical influence of dust aerosols acting as cloud condensation nuclei or ice nuclei is not included in the model setup. Only the direct and semi-direct radiative effects are considered in our study. As the cloud cover calculations in the model are rele- vant to the RH and $T$ changes, the cloud-induced semi-direct effect is indeed represented as a consequence of the direct effect in the model. Because the model setup is not able to simulate microphysical effects related to dust, our focus is on thermodynamic changes that mainly influence area-mean profiles of temperature and moisture that define the environment for moist convection. Thus, the relationship to cyclogenesis centers on the mechanism by which convection is favored or suppressed by the dust-radiation interaction interaction over a region that includes a nascent cyclone, not on detailed cloud processes within that region.

\section{Results}

\subsection{Verification of assimilated dust outbreaks}

Figure 2 shows the 2006 July, August, and September periodaveraged $550 \mathrm{~nm}$ AOD in the assimilation experiment compared with Level-3 OMI/Aura $483.5 \mathrm{~nm}$ AOD in the study domain. Model-simulated results are from the $6 \mathrm{~h}$ forecast valid at 18:00 UTC, which is closest to the OMI pass time. As the OMI data only provide the $342.5,388.0,442.0,463.0$, and $483.5 \mathrm{~nm}$ AOD, no direct comparison to $550 \mathrm{~nm}$ AOD can be made. High $550 \mathrm{~nm}$ AOD (0.4-0.7) over the Atlantic 

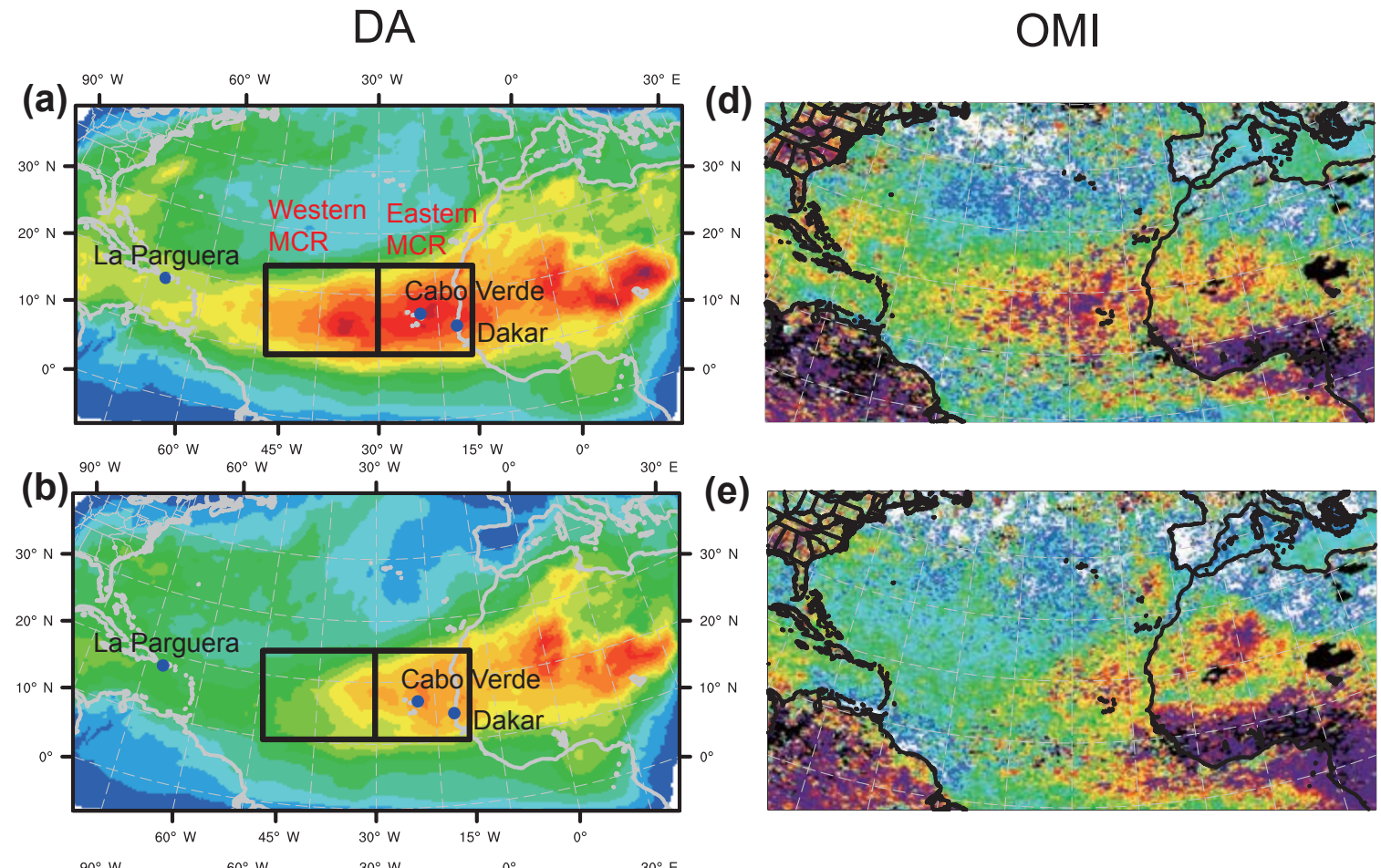

(e)
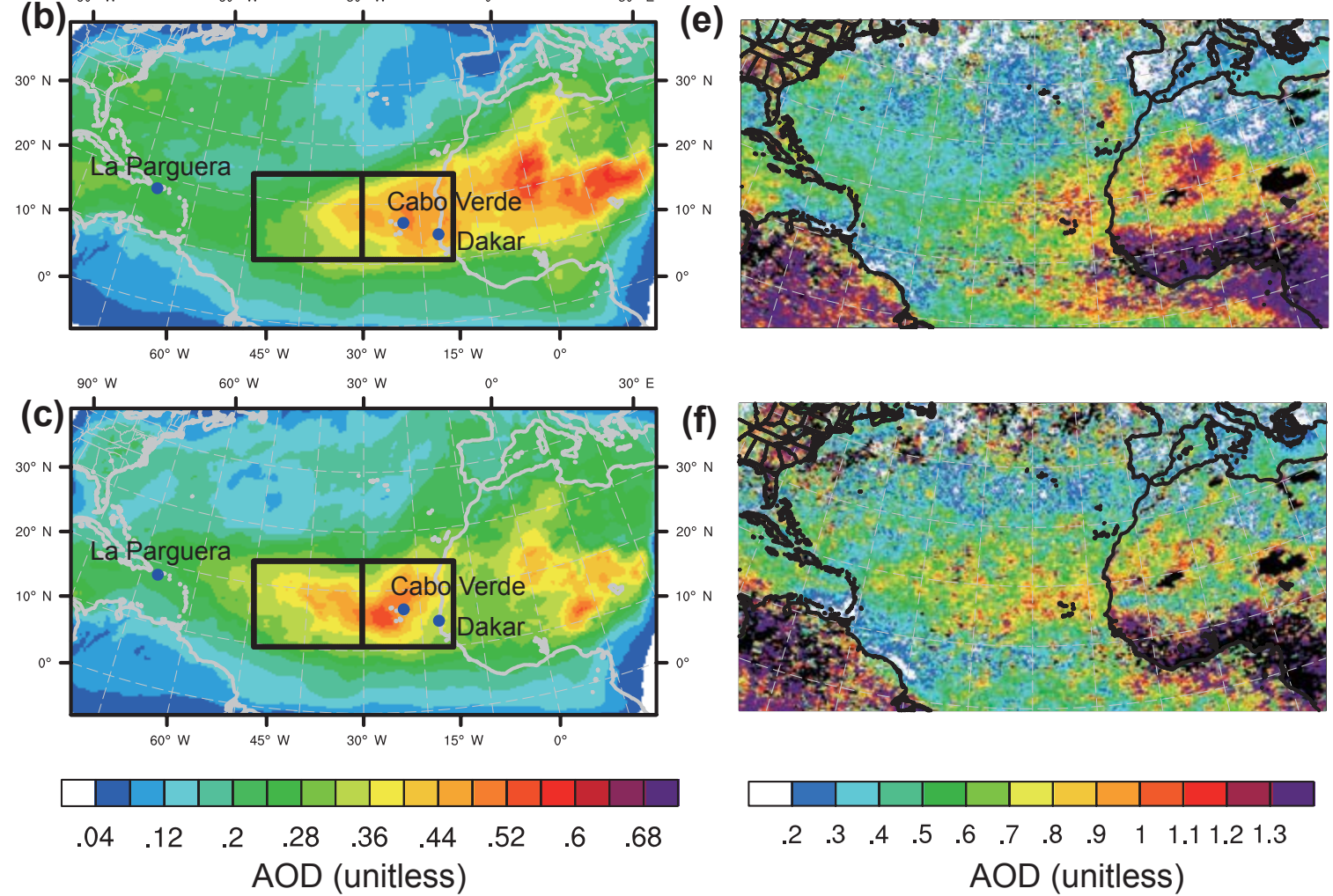

Figure 2. Time-averaged $550 \mathrm{~nm}$ AOD in data assimilation experiment (left) compared with Level-3 OMI/Aura 483.5 nm AOD (right), Averaged period: 8-31 July (a, d), 1-31 August (b, e), and 1-17 September (c, f). The rectangles are defined as the main cyclogenesis region (MCR), including the eastern MCR and the western MCR. The blue dots (left panels) are the AERONET sites used in Fig. 3. The scales on the left and right color bars are different.

Ocean is shown in the DA experiment. Although the simulated $550 \mathrm{~nm}$ AOD values are still lower than the OMI $483.5 \mathrm{~nm}$ AOD, the locations and shapes of the dust tongues are well represented. The black rectangles define the main dust region and also the main cyclogenesis region (MCR). To distinguish the effects near to and far from the dust source region, the MCR is divided into two regions: the eastern MCR (east of $30^{\circ} \mathrm{W}$ ) and the western MCR (west of $30^{\circ} \mathrm{W}$ ).

The simulated $550 \mathrm{~nm}$ AODs at three AERONET sites along the dust transport path are also shown in Fig. 3 to verify the aerosol DA performance. The locations of the three
AERONET sites are shown as blue dots in Fig. 2 (left panel). The observations obtained from AERONET are interpolated to $550 \mathrm{~nm}$ for comparisons (Eck et al., 1999). At Cabo Verde and Dakar sites near the dust source region, high AOD values during the dust outbreak periods were successfully reproduced. At La Parguera near the end of the dust path, the simulation also captured the AOD fluctuations well.

It is also important to verify the vertical distributions of AOD in the model, as the semi-direct effect of dust is sensitive to the position of the dust layer with respect to clouds. Figure 4 shows the vertical distributions of modeled $550 \mathrm{~nm}$ 

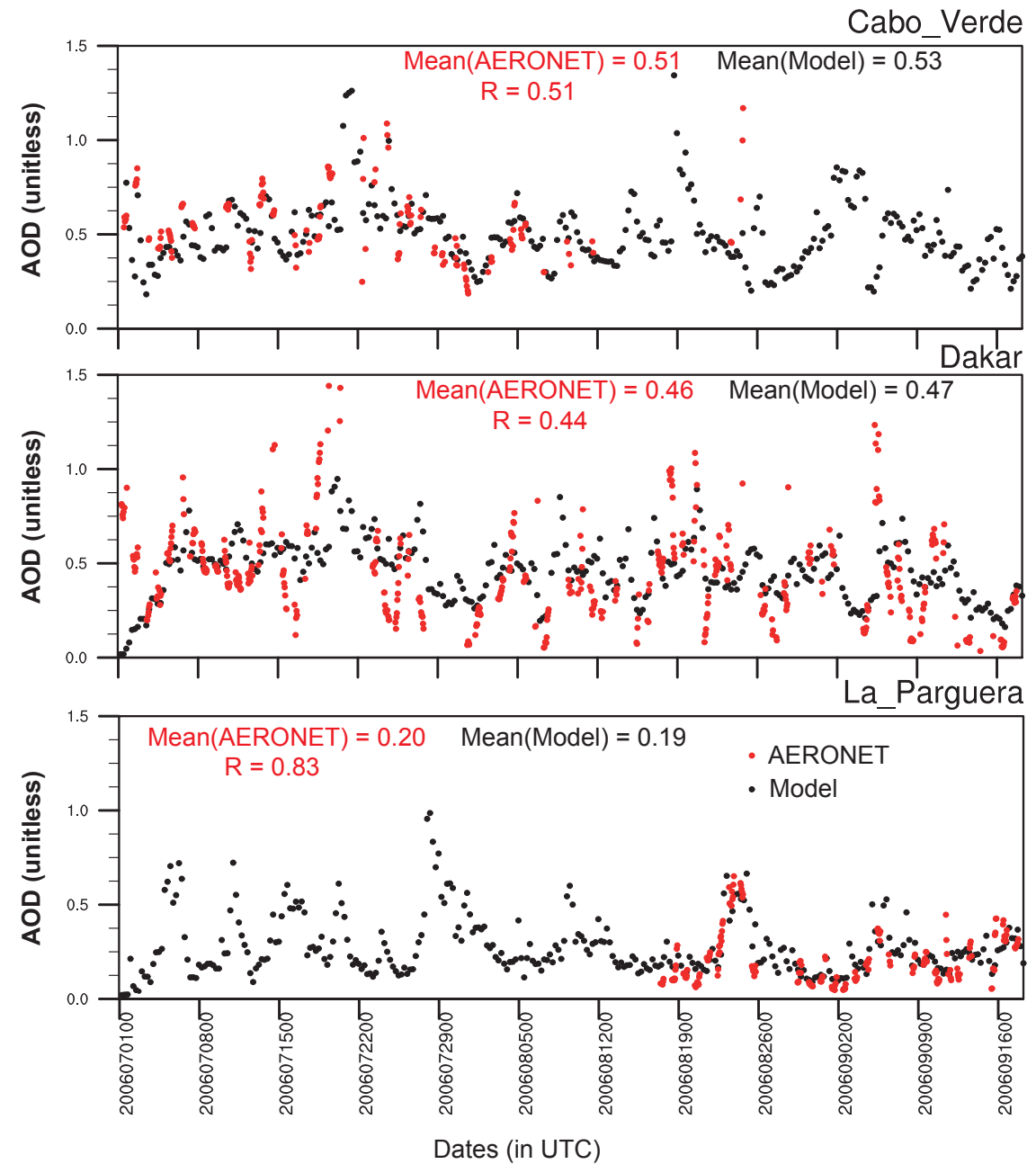

Figure 3. Model-simulated $550 \mathrm{~nm}$ AOD (black) and AERONET $550 \mathrm{~nm}$ AOD (red) at three sites. The locations of the three sites are shown as blue dots in Fig. 2 (left panels).

AOD compared to AOD retrievals from the Cloud-Aerosol Lidar with Orthogonal Polarization (CALIOP) instrument onboard the Cloud-Aerosol Lidar and Infrared Pathfinder Satellite Observations (CALIPSO) satellite (Winker et al., 2009). The CALIOP AOD product is provided at $5 \mathrm{~km}(60 \mathrm{~m})$ horizontal (vertical) resolution and was averaged to match the model resolution $(36 \mathrm{~km})$ and vertical grid before comparing to the model output. As the CALIPSO path is rather narrow and data availability is limited, it is difficult to find matching dust outbreak cases without any missing data. Here three cross sections along CALIPSO paths on 29 July and 5 September are shown. The outbreaks of Saharan dust and the westward transport are shown on both days (left panels). In addition, the top-left panel on 29 July shows a maximum of AOD in the western Atlantic which is caused by an earlier dust outbreak on 23 July (not shown). Although CALIPSO shows more high AOD values below $500 \mathrm{~m}$ over the ocean, the overall patterns of the model-simulated AOD are similar to CALIPSO observations with high AOD values around
$4 \mathrm{~km}$ near the source region (top panel) which extended to lower levels (below $2 \mathrm{~km}$ ) over the ocean.

\subsection{Dust-induced vertical thermodynamic structure changes}

Given reliable dust fields and associated optical properties with the assimilation of MODIS AOD, the forecast differences between RE_ON and RE_OFF allow us to have a better understanding of the dust radiative effect and its feedback on the thermodynamics and dynamics. The analysis in this section is based on the hourly output from the first $96 \mathrm{~h}$ of all forecasts from 8 July to 18 September. To distinguish the effects near and far from the African coast, the analysis is conducted for the eastern MCR (near-desert region) and the western MCR (far-from-desert region) separately (Fig. 2). To understand the effects of the vertical distribution of dust, the averaged AOD vertical profiles for both the eastern MCR and western MCR are given in the contoured frequency al- 

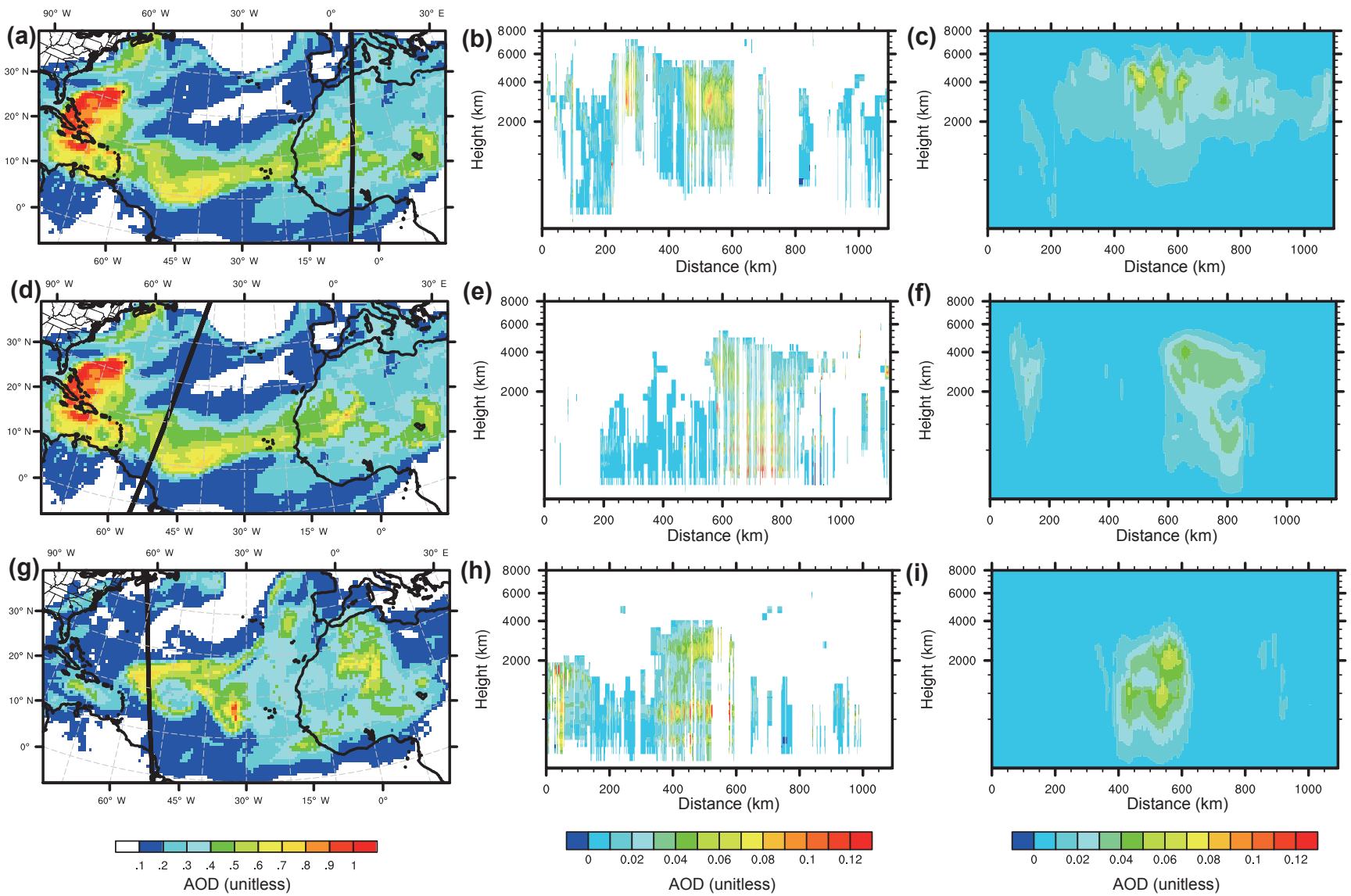

Figure 4. Model $550 \mathrm{~nm}$ AOD forecasts (a, d, $\mathbf{g}$ ) overlaid with CALIPSO path (black thick lines) and corresponding vertical distributions of CALIOP AOD (b, e, h) and modeled AOD (c, f, i) at around 01:00 UTC (a-c) and 05:00 UTC (d-f) on 29 July and 16:00 UTC on 5 September $(\mathbf{g}-\mathbf{i})$.
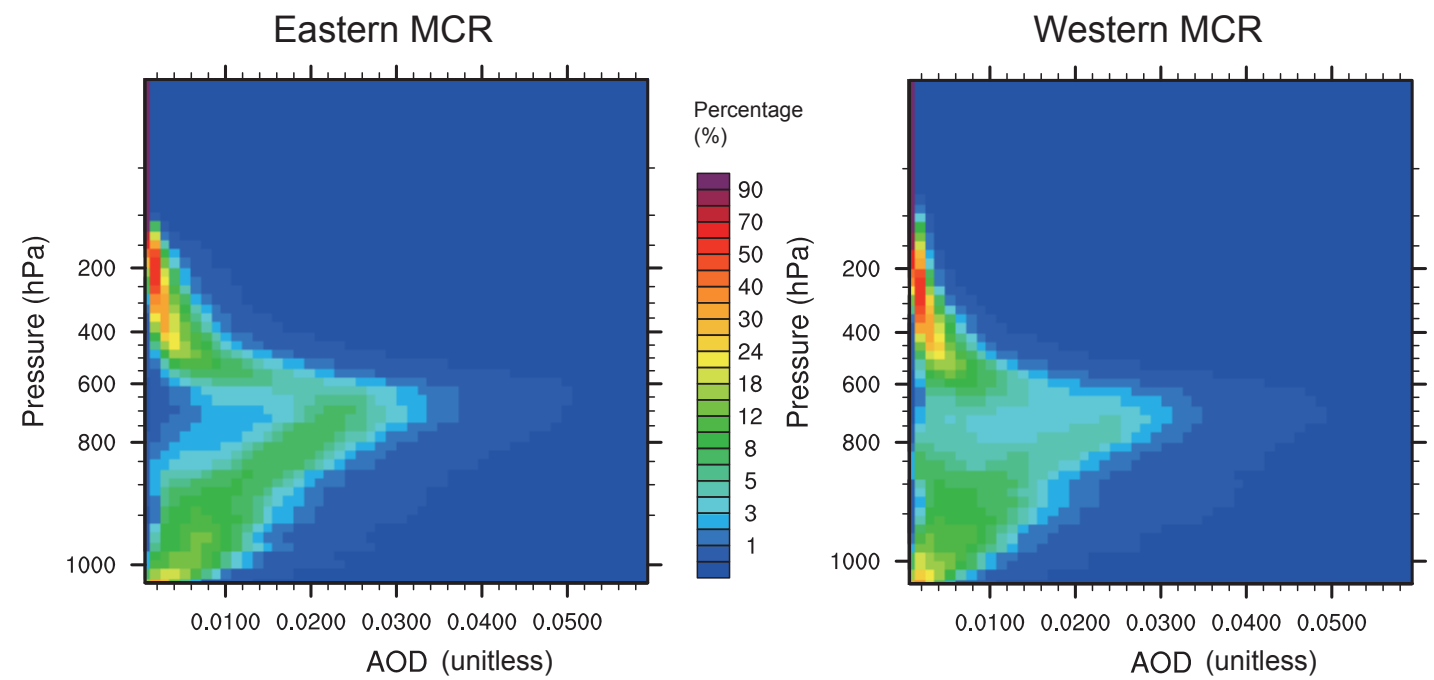

Figure 5. AOD CFADs (contoured frequency altitude diagrams) for the eastern and western MCR regions (based on the first $96 \mathrm{~h}$ forecasts for 8 July-18 September). 
titude diagrams (CFADs) in Fig. 5. The frequencies in the eastern MCR show that the dust from the Sahara desert is mostly elevated during the westward transport process and the AOD peaks at $700 \mathrm{hPa}$ with values around $0.02-0.03$. In the western MCR, high AOD can be frequently found at 900 $950 \mathrm{hPa}$. There are also few cases of deep layers of dust that are not elevated to $700 \mathrm{hPa}$ altitude but with relatively high AOD below $850 \mathrm{hPa}$. For the western MCR, the frequencies of deep layers of dust are higher than those in the eastern MCR indicating the dust depositing process along the transport path.

To be consistent in the two regions and to distinguish the two types of structures, we define the cases of "deep layer of dust" as AOD larger than 0.015 at 900 or $950 \mathrm{hPa}$ but smaller than 0.02 at $700 \mathrm{hPa}$. The total sampling ratios are 8.5 and $10.7 \%$ in the eastern and western MCR respectively. As the remaining cases show the common characteristic of elevated dust (high AOD elevated at $700 \mathrm{hPa}$ ), we also categorized them as the second type - "elevated dust". It should be noted that "deep layer of dust" actually means that the high AOD are mostly located below $700 \mathrm{mb}$ (not really deep). For the four types of dust ("elevated dust"/"deep layer dust" in the eastern/western MCR), thermodynamic/dynamic changes in the first $96 \mathrm{~h}$ between RE_ON and RE_OFF were averaged hourly for the 8 July-18 September forecasts. The changes (RE_ON - RE_OFF) in temperature, relative humidity, vertical velocity $(W)$, convective inhibition, and buoyancy for boundary layer parcels are shown as pressure-forecast time series in Figs. 6-9a. To investigate how the clouds were changed due to dust-induced heating effects and also to separate the changes by short- and longwave cloud radiative effects, the mixing ratios of clouds (liquid plus ice water) and the differences of temperature tendencies $\left(\mathrm{K} \mathrm{day}^{-1}\right)$ due to longwave and shortwave radiative effects are also given in Figs. 6-9b-c. To show statistical significance of the results, the CFADs of AOD, differences of temperatures at $36 \mathrm{~h}$ forecast, and also histogram statistics at dust layers are given in Figs. 6-9d. To check the thermodynamic budget, temperature tendency differences from all the contributions, including radiative heating; vertical mixing from the planetary boundary layer (PBL) process, cumulus process, diabatic heating, total advective processes; and the sum of the five parameters are given in Figs. 6-9e. The only contribution that is not readily available from the model is the heating term due to horizontal diffusion which would probably be part of a residual. The term from total advective processes includes both horizontal advection and vertical advection. As horizontal advection becomes less important as the box size increases, the term of total advective process mainly reflects the vertical advection, including the vertical transport of heat (temperature) and the adiabatic cooling. Condensational or phase change term can be expressed as the sum of cumulus and diabatic heating.

For the "elevated dust" in the eastern MCR (Fig. 6), the dust was more concentrated above the top of the boundary layer (Fig. 6a). Significant positive $T$ anomalies occur around $600-800 \mathrm{hPa}$ due to the dust radiative absorption, and the warming has a diurnal variation with the largest signal during the strongest solar heating period (12:00-18:00 UTC). The CFADs of AOD and temperature differences at $36 \mathrm{~h}$ forecast (valid at 12:00 UTC, left and middle panels of Fig. 6d) show that the largest temperate anomalies are right at the altitude where AOD is highest and the histogram at that layer (right panel of Fig. 6d) shows the mean temperature differences reach $0.08^{\circ}$, indicating that the result is statistical significant. Obvious negative $T$ anomalies occur both above and below the dust. The negative $T$ anomalies above the dust lag the positive anomalies within the dust and also have a diurnal variation. Below the dust, negative $T$ anomalies start to occur from the night of the 2nd day and do not have a significant diurnal cycle above $950 \mathrm{hPa}$, but the anomalies extend to lower atmosphere during the morning (07:00-12:00 UTC). Correspondingly, positive $\mathrm{RH}$ anomalies also occur below the dust layer above $950 \mathrm{hPa}$, and the changes show as early as in the night of the 1st day - several hours after the strong radiative heating during the first afternoon. The positive $\mathrm{RH}$ anomalies have a similar pattern as that of the $T$ anomalies just above the PBL, in terms of occurrence time and vertical structure after the 2nd day. As the clouds fields (Fig. 6b) show no significant low-cloud changes and heating rate changes due to $\mathrm{LW}$ (Fig. 6c) at the $800-950 \mathrm{hPa}$ layer, the cooling below $800 \mathrm{hPa}$ may result from the adiabatic upward motion driven by the heating above, similar to the "elevated heat pump" mechanism (Lau et al., 2006, 2009; Gu et al., 2016). Among all the contributions that caused the temperature tendency differences (Fig. 6e), the contribution from the advective process is the most prominent in addition to the radiative heating. It caused large negative anomalies below $200 \mathrm{hPa}$, and the changes started from 12:00-13:00 UTC in day 1, a few hours after the heating started, indicating important vertical advection changes after the radiative heating process. It is also consistent with the assumption of the adiabatic cooling effect as mentioned above. It should be noted that $T$ and $\mathrm{RH}$ anomalies above the dust layer strengthen with time, although the elevated AOD weakens, while strong high ice clouds and heating rate changes above $600 \mathrm{hPa}$ were also seen.

It is notable that although the dust-absorbing-induced heating occurs at $700 \mathrm{hPa}$, the changes of temperature and other thermodynamic parameters occur not only in the dust layer but also far from the source. Specifically, the $T$ anomalies show features that are very similar to the internal gravity wave caused by buoyancy oscillation. It is assumed that the dust-induced heating played as a forcing that caused effects far from the source through upward propagating gravity waves. This is a possible paradigm shift in the way we think of the total response from a direct effect of aerosols when the aerosol has a mesoscale organizational structure. Compared to the internal gravity wave caused by buoyancy oscillation, the only difference is that the dust-induced heating force is much stronger and lasts for a few hours, thus 
(a) Thermodynamic changes
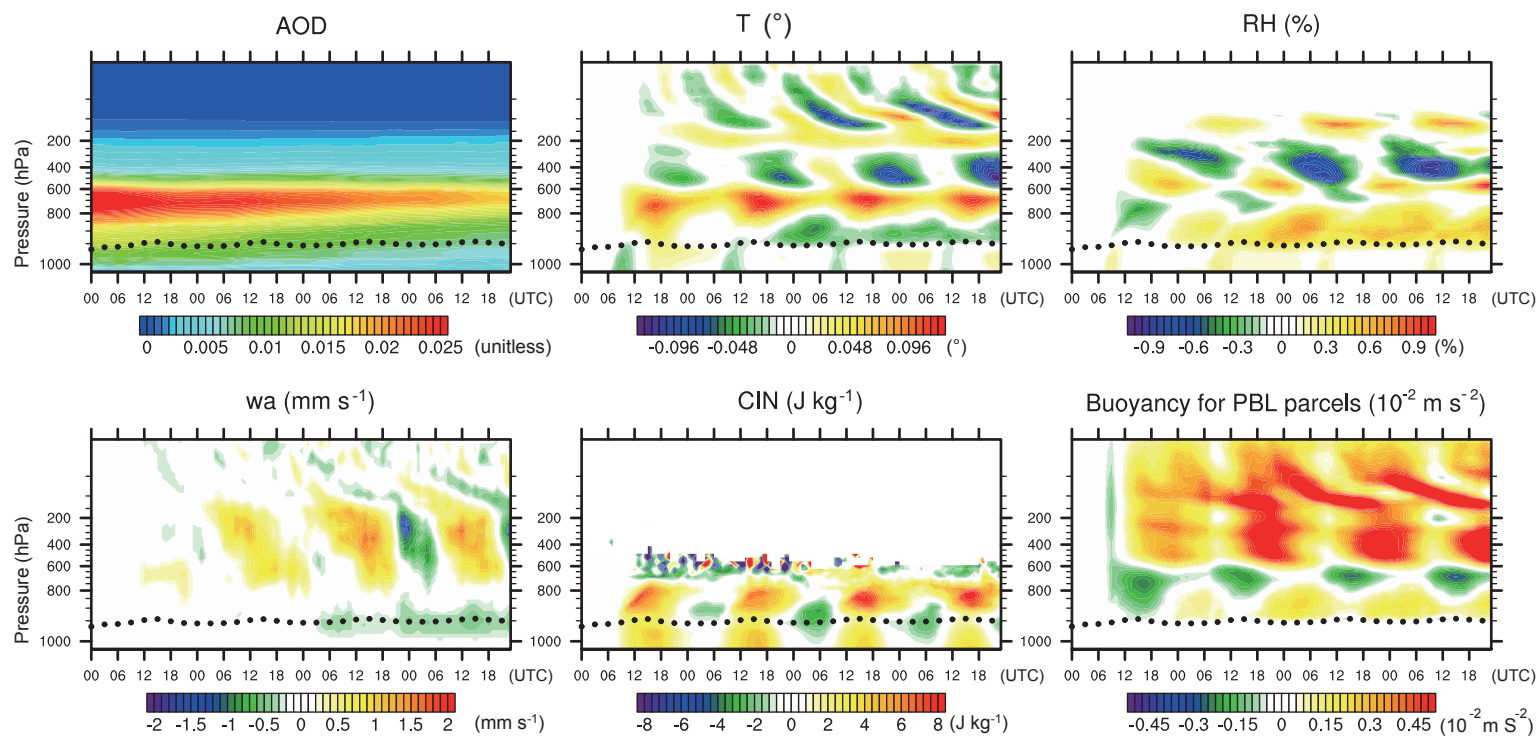

Buoyancy for PBL parcels $\left(10^{-2} \mathrm{~m} \mathrm{~s}^{-2}\right)$

(b) Mixing ratios of clouds (liquid plus ice water) $\left(\mathrm{mg} \mathrm{kg}^{-1}\right)$
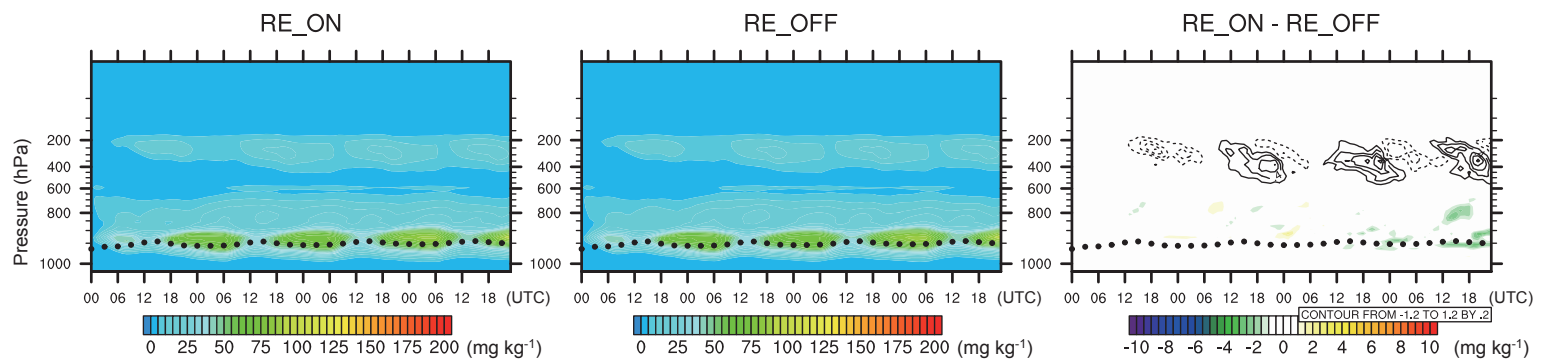

(c) The differences (RE_ON - RE_OFF) of heating rates $\left(K_{\text {day }}{ }^{-1}\right)$

LW

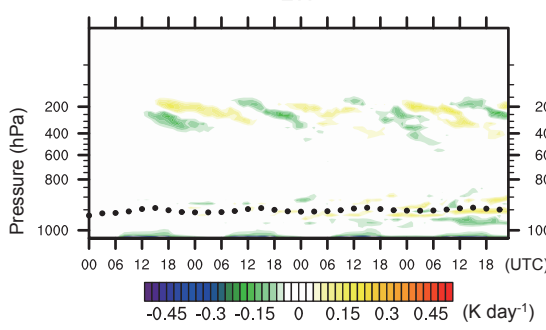

SW

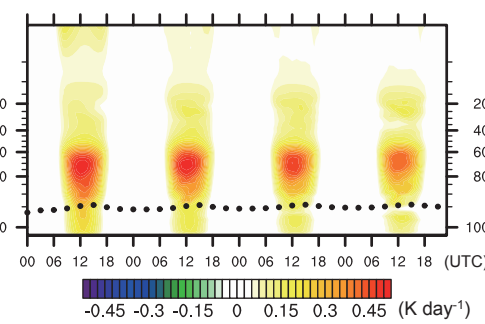

$\mathrm{LW}+\mathrm{SW}$

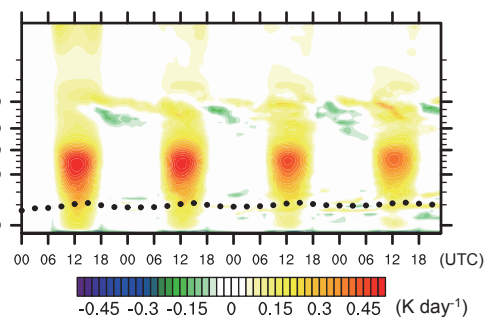

Figure 6.

the wave propagation is also stronger. In addition, it is a periodic forcing (strongest during the afternoon and weakest during the night), thus the vertical patterns also have diurnal cycles accordingly. Furthermore, because waves are excited in the stratified background state, they propagate vertically and influence temperature and RH changes far from the source. In particular, we guess that is what is happening to the ice clouds. The upward motion from the waves increases the nucleation of ice; subsidence decreases it. As the period heat source occurs every $24 \mathrm{~h}$ and lasts for a few hours, the propagation of the gravity wave strengthens horizontally and vertically as time increases.

From the aspect of effects to convection, the cooling and moistening at $850-950 \mathrm{hPa}$, above the top of the boundary layer, leads to significant reduction of CIN during the nighttime. It should be noted that CIN is calculated for parcels lifted from each pressure level, and Fig. 6a shows the value of CIN plotted at the parcel origination level. Buoyancy differences for boundary layer parcels more clearly correspond to differences in temperature above the boundary layer (Fig. 6a). In the cases that boundary layer parcels are not 


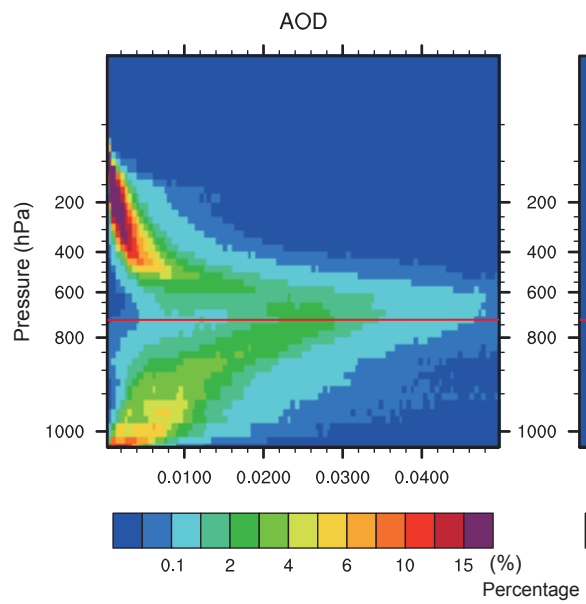

(d) Statistics at $36 \mathrm{~h}$ forecast

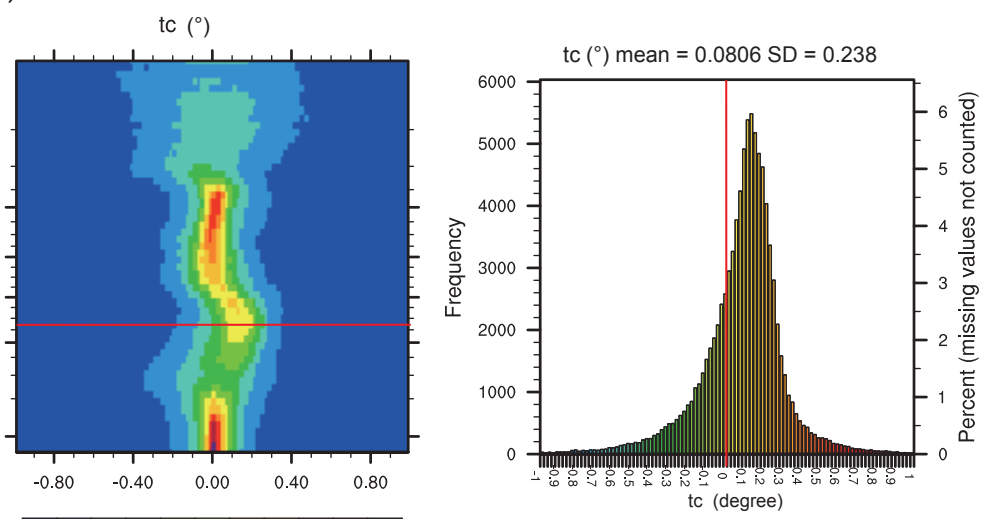

Histogram at $730 \mathrm{hPa}$

(e) Temperature tendency differences (RE_ON - RE_OFF) from five contributions (K day-1)
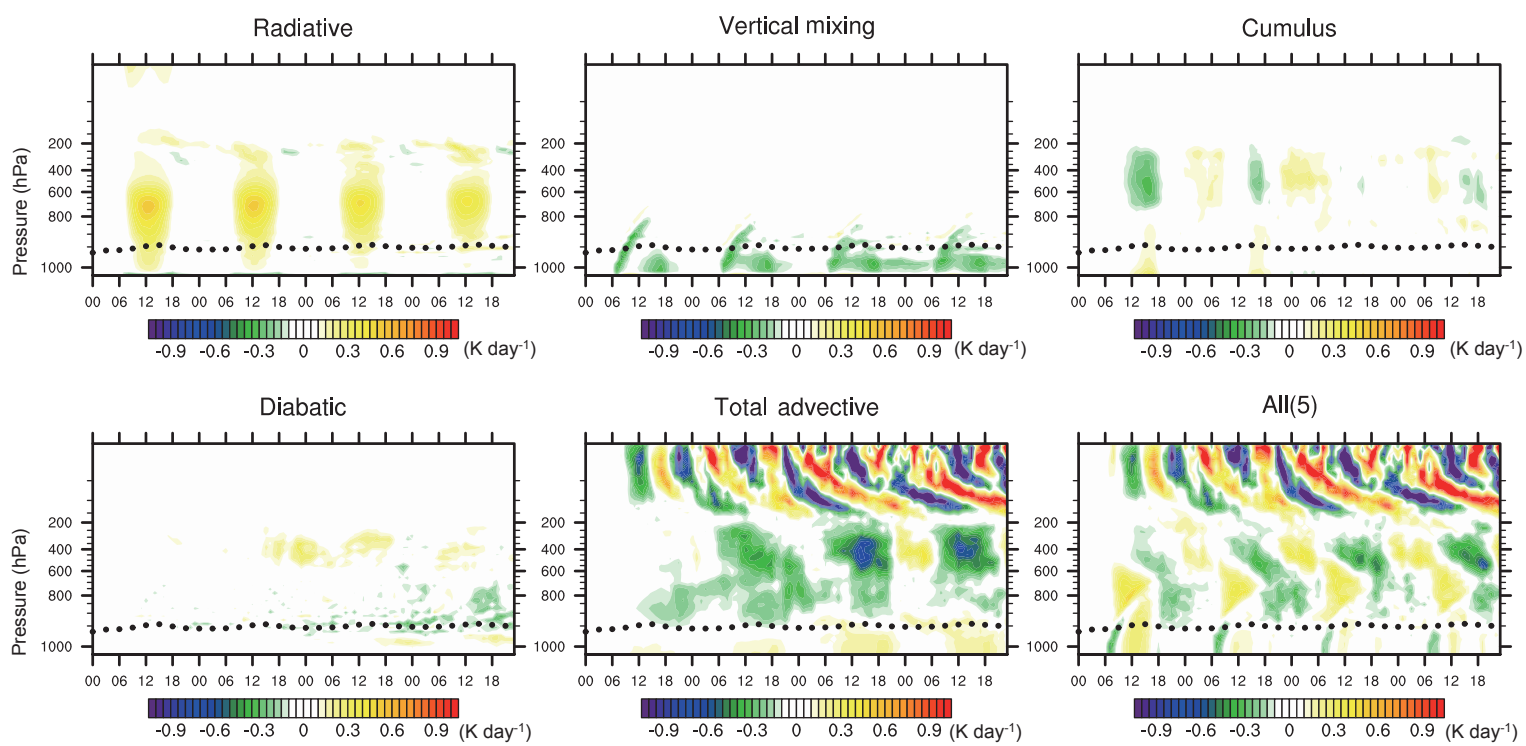

Figure 6. Averaged parameters as a function of pressure layers in $\mathrm{hPa}(y$ axis) and the first $96 \mathrm{~h}$ forecast time ( $x$ axis, in UTC time) of the "elevated dust" in the eastern MCR from two experiments (8 July-18 September). (a) AOD from RF_ON and differences (RE_ON RE_OFF) for temperature $\left({ }^{\circ}\right)$, relative humidity $(\%)$, vertical velocity $\left(\mathrm{mm} \mathrm{s}^{-1}\right), \mathrm{CIN}\left(\mathrm{J} \mathrm{kg}^{-1}\right)$, and buoyancy for boundary layer parcels $\left(10^{-2} \mathrm{~m} \mathrm{~s}^{-2}\right)$. (b) Mixing ratios of clouds (liquid plus ice water; $\mathrm{mg} \mathrm{kg}^{-1}$ ); the RE_ON - RE_OFF differences of ice clouds were given as contour lines (negative values in dash lines). (c) The differences of heating rates (K day ${ }^{-1}$ ) due to $\mathrm{LW}, \mathrm{SW}$, and $\mathrm{LW}+\mathrm{SW}$ radiative effects respectively. Black dots indicate the top of the boundary layer. (d) Statistics at $36 \mathrm{~h}$ forecasts. The left and middle panels are the CFADs of AOD and differences (RE_ON - RE_OFF) of temperature respectively. The right panel is the histogram of temperature differences at certain levels (indicated as horizontal red lines in the left and middle panels). The vertical red line in the right panel is the line of value zero. (e) Temperature tendency differences (RE_ON - RE_OFF) from five contributions, including the radiative process, vertical mixing by PBL process, cumulus process, diabatic heating, total advective process, and the sum of the five processes. Units: $\mathrm{K}^{-1}{ }^{-1}$.

strongly negatively buoyant, decreased CIN/increased buoyancy just above the top of the boundary layer may weaken the inversion and lead to the destabilization of the lower troposphere with respect to deep convection.

For the "elevated dust" in the western MCR (Fig. 7), the warming due to dust is stronger than that in the eastern MCR, but no cooling occurs below the dust layer, although moist- ening is still present (Fig. 7a). The differences of the temperature anomalies above the boundary layer in the two regions may come from the different clouds and heating rate changes (Figs. 6b, c, e and 7b, c, e). In both the western and eastern MCR, the low clouds are right at the top of the boundary layer. In the western MCR, the cloud amounts are larger than in the eastern MCR (as the air becomes moister from 
(a) AOD (RE_ON) and thermodynamic differences (RE_ON - RE_OFF)
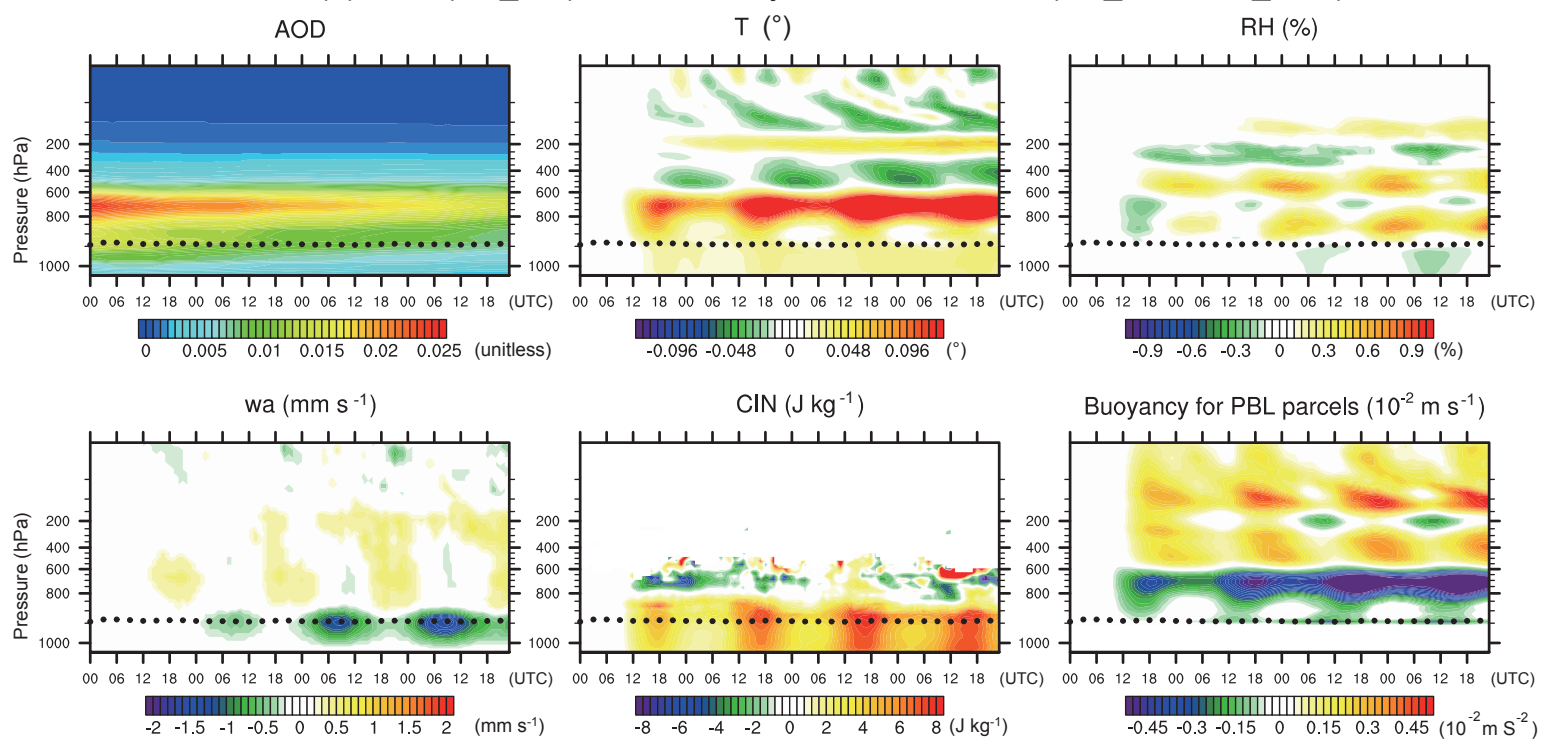

(b) Mixing ratios of clouds (liquid plus ice water) $\left(\mathrm{mg} \mathrm{kg}^{-1}\right)$

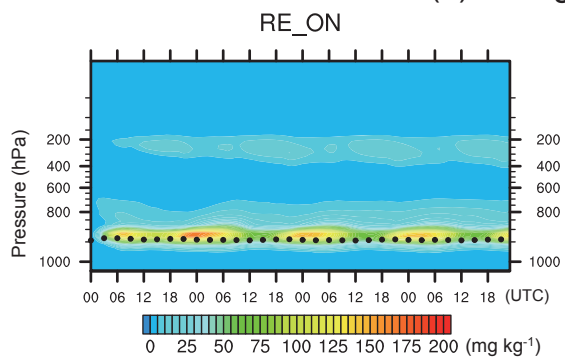
RE_OFF

RE ON - RE_OFF

LW

(c) The differences (RE_ON - RE_OFF) of heating rates $\left(\mathrm{K}_{\text {day }}{ }^{-1}\right)$

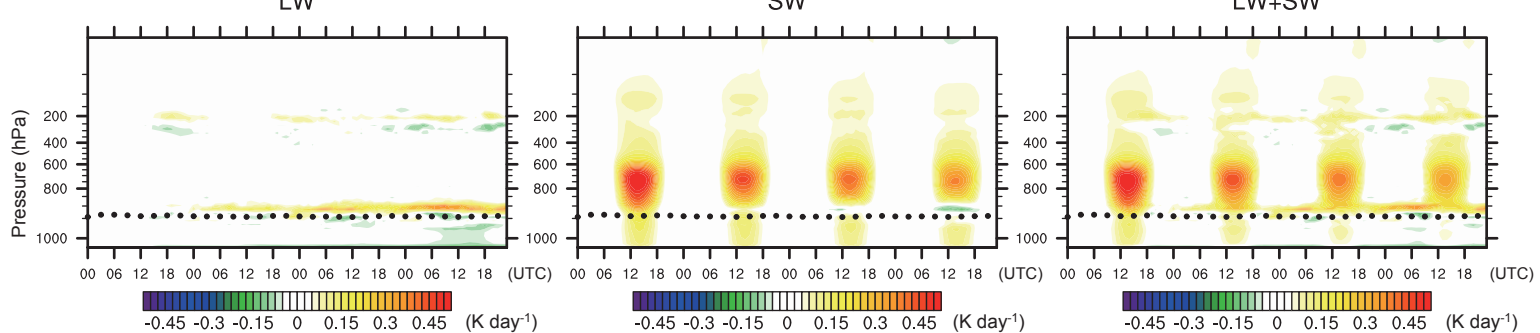

Figure 7.

eastern to western MCR), and the cloud changes are also more prominent. As the dust is concentrated immediately above the low clouds, it is possible that the cloud concentrations are decreased at $900-950 \mathrm{hPa}$ due to the evaporation effect. As the longwave radiation of dust is not included in the model, the heating rate changes due to LW are mainly from the changes of clouds. As cloud-top cooling and cloudbottom heating normally occur associated with longwave radiative effects (Fu and Liou, 1993), the vertical changes of clouds cause significant positive heating rate anomalies at 900-950 hPa for the western MCR (Fig. 7c) that offset the adiabatic cooling there. Compared to the case in the eastern MCR, the cloud changes are significant and the cooling due to advection is much weaker in the western MCR (Figs. 7e and 6e), thus the positive temperature anomalies are much larger. Unlike the cooling near the surface in the eastern MCR, slight warming occurs in the western MCR. It is noticeable that the vertical velocity also starts to show negative anomalies at the top of the boundary layer from the 2nd day, which becomes prominent on the 3rd day. Weakened upward motion, or strengthened downward motion, is consistent with the CIN increase there. 
(d) Statistics at $36 \mathrm{~h}$ forecast
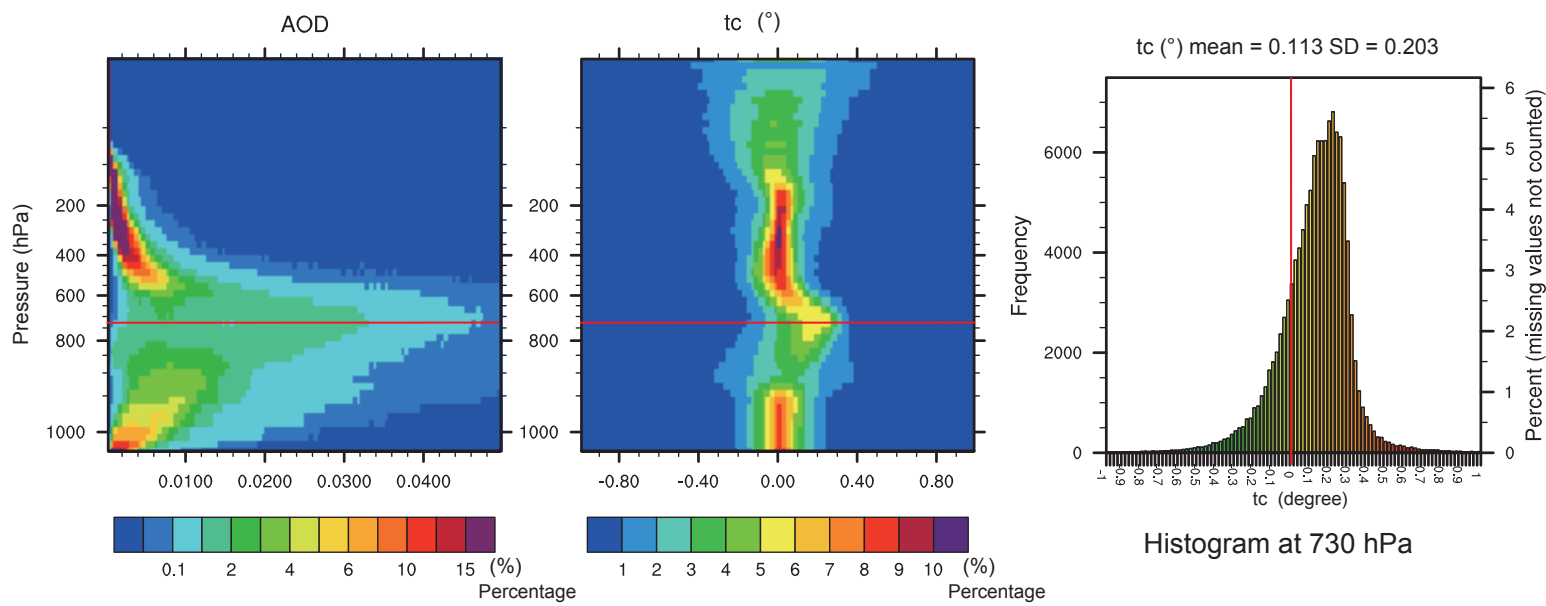

Histogram at $730 \mathrm{hPa}$

(e) Temperature tendency differences (RE_ON - RE_OFF) from five contributions (K day $\left.{ }^{-1}\right)$
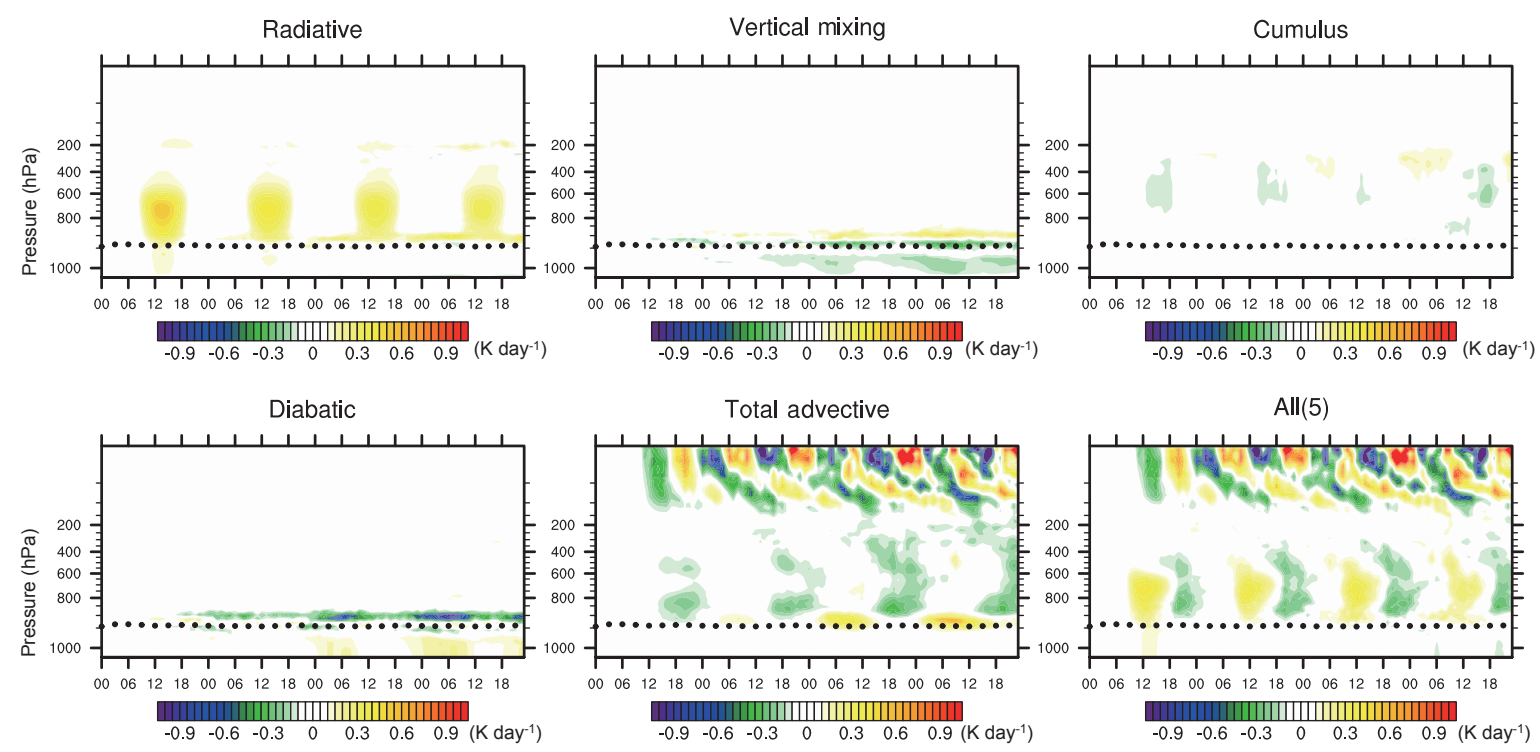

Figure 7. Same as Fig. 6 but for the "elevated dust" in the western MCR.

For the "deep layer of dust" in the eastern MCR (Fig. 8), the dust layers are thicker than those of "elevated dust" and extend into the boundary layer. The dust absorption causes large positive temperature anomalies below $800 \mathrm{hPa}$ starting from the 1st day. But the temperature changes become more complicated from the 3rd day when the cloud changes are more prominent. As the dust not only covers the low-cloud layer but also extends to the altitudes above the cloud layer, low clouds change in a mixed manner and redistribute vertically - decreasing at the top of the boundary layer and increasing at the altitudes above. The changes in low level clouds lead to an increase in heating rate around $900 \mathrm{hPa}$ and a slight LW decrease below $900 \mathrm{hPa}$. In addition to the changes of low liquid clouds at low levels, ice clouds at high levels also change (mostly increase) significantly. While out- going longwave is mostly controlled by high clouds, it might be the reason for the other maximum differences of heating rates around $200-400 \mathrm{hPa}$. According to the thermodynamic budget (Fig. 8e), we tried to understand the whole process: maximum warming happens at about $900 \mathrm{mb}$ (just above the boundary layer), which seems to destabilize the atmosphere and results in the vertical development of cumulus (as also shown in latent heat release by cumulus), with enhanced ice cloud water but reduced liquid cloud water; cooling from the 3rd day is because the advective (or adiabatic) cooling exceeds the heating effect of dust. Since the process becomes rather complex from the 3rd day, only the results of the first 2 days for this type of dust are taken into account in our hypothesis later. 
(a) AOD (RE_ON) and thermodynamic differences (RE_ON - RE_OFF)
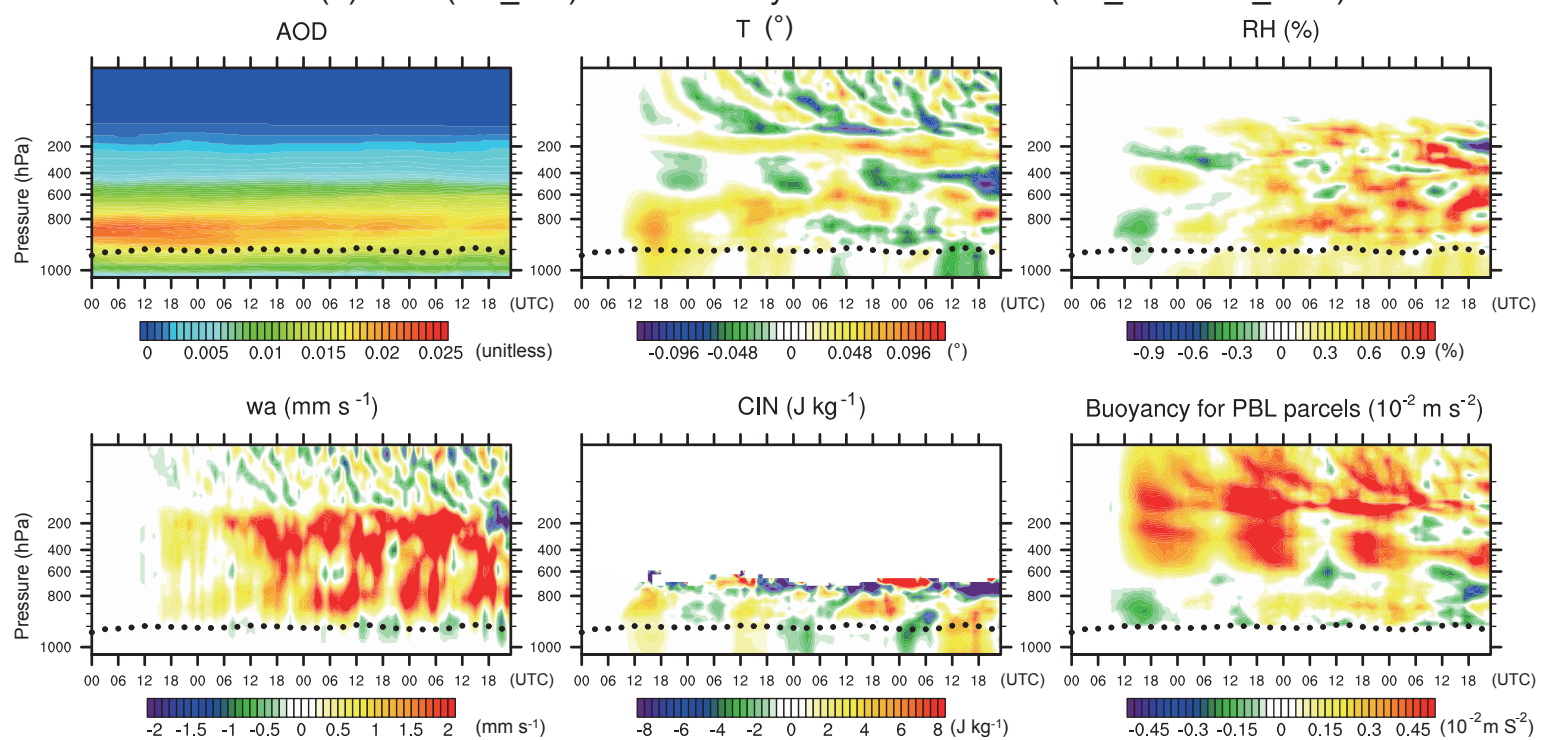

(b) Mixing ratios of clouds (liquid plus ice water) $\left(\mathrm{mg} \mathrm{kg}^{-1}\right)$
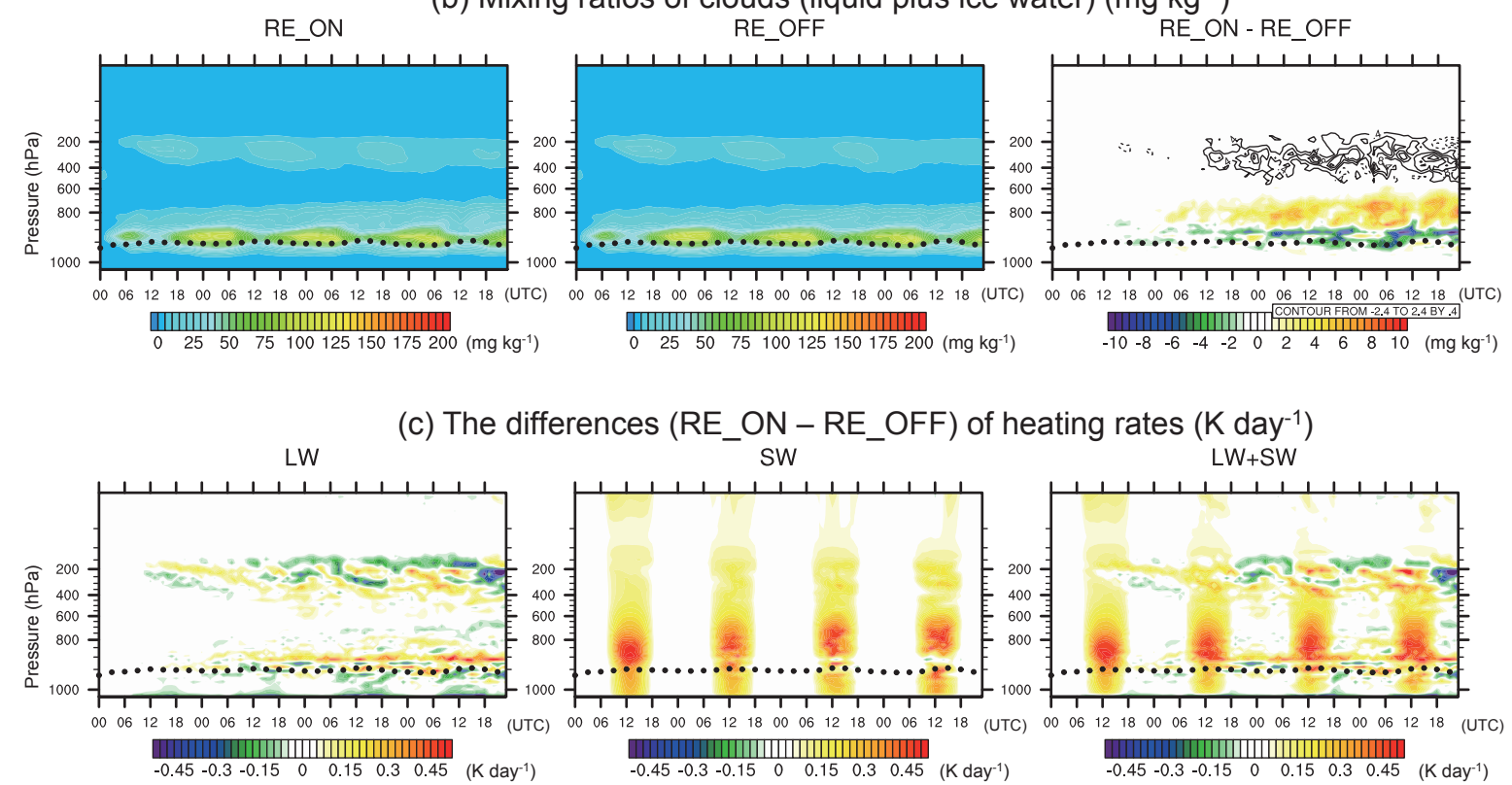

Figure 8.

The changes in cases of "deep layer of dust" in the western MCR (Fig. 9) are more explainable. In addition to the dust-absorption-induced heating above the boundary layer, the vertical changes of low-level clouds also lead to large positive heating rate changes at $900 \mathrm{hPa}$ which enhance the positive temperature anomalies and CIN increase there. Ice clouds both increase and decrease during different times, which leads to a less coherent signal at high levels. Similar to the case of "elevated dust" in the western MCR (Fig. 7), vertical velocity starts to decrease at the top of the boundary layer from the 2 nd day, and this becomes prominent from the 3rd day onward. The statistics here (Figs. 6-9) show how dust induces changes of temperature, and also cloud, in the lower troposphere that modulate convective inhibition.

\subsection{Synthesis}

\subsubsection{Effect on deep convection}

Based on the above statistics in Sect. 3.2, we hypothesize that in the early stage of forecasts the altitude of the dust determines whether there is warming or cooling just above the top of the boundary layer. Convection is sensitive to temper- 
(d) Statistics at $36 \mathrm{~h}$ forecast
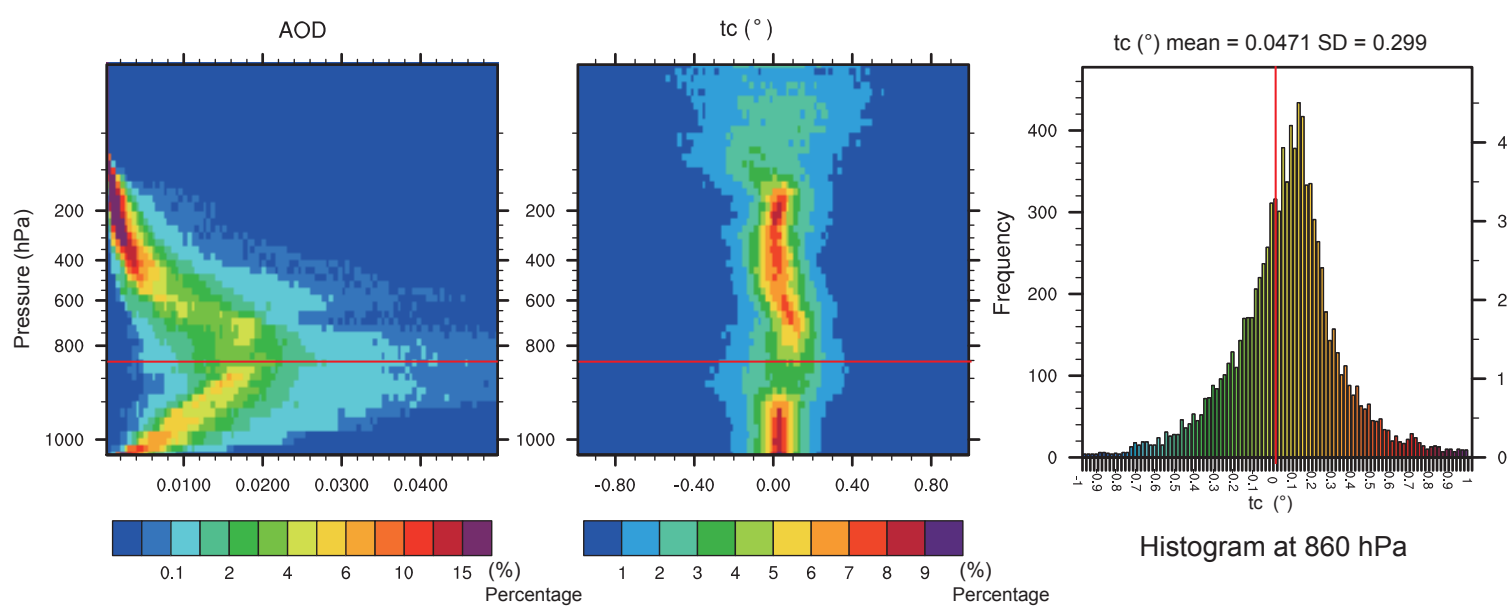

Histogram at $860 \mathrm{hPa}$

(e) Temperature tendency differences (RE_ON - RE_OFF) from five contributions ( $K$ day $^{-1}$ )
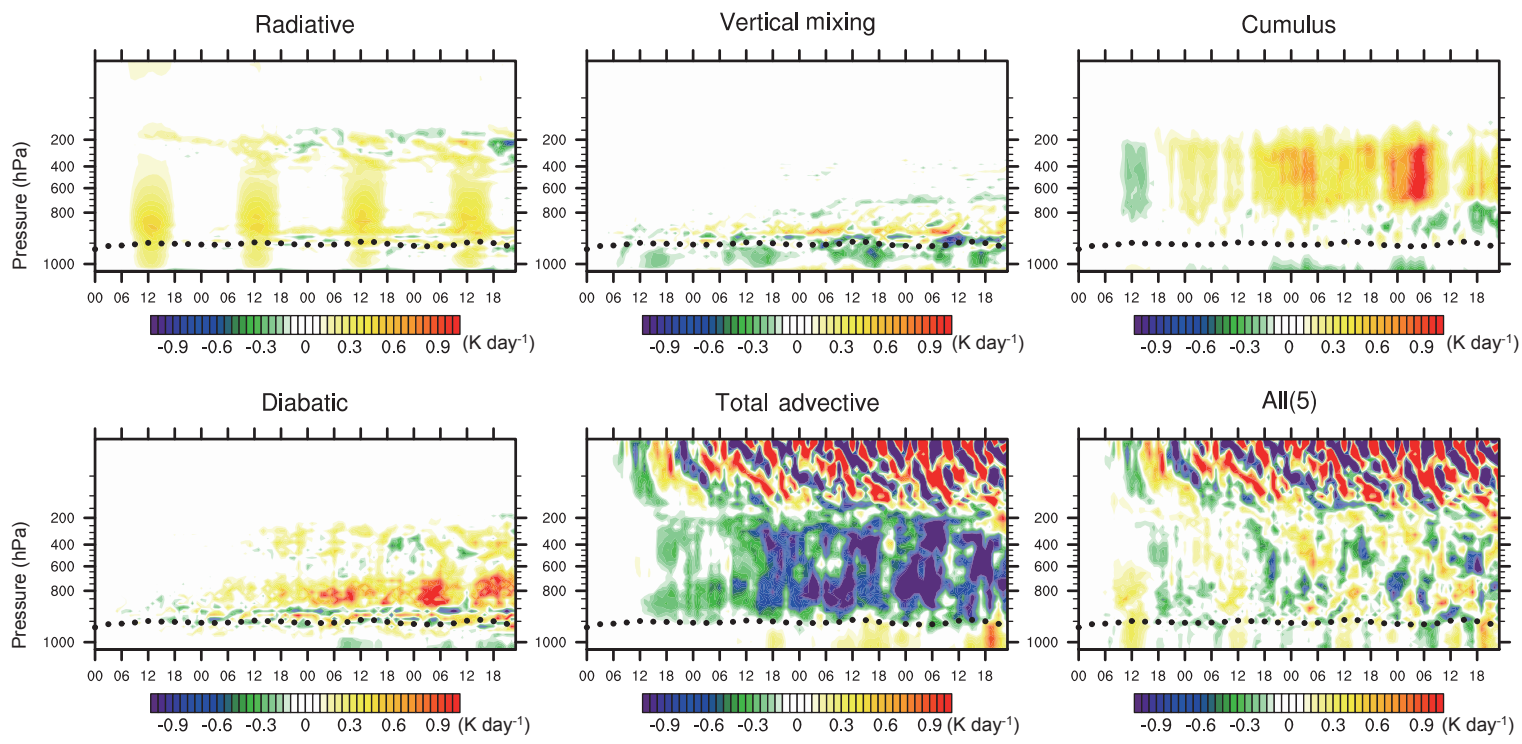

Figure 8. Same as Fig. 6 but for the "deep layer of dust" in the eastern MCR.

ature changes just above the boundary layer because this is the layer in which convective inhibition is typically found. For this region, CIN is also very sensitive to the $700 \mathrm{hPa}$ temperature. In the cases where significant heating occurs just above the boundary layer (deep layer of dust in the eastern and western MCR) or at the 700-800 hPa layer (elevated dust in the western MCR), at an elevation where there might be already some convective inhibition, the heating makes the inhibition stronger. This suppresses convection and prevents the TC development. With elevated dust, the heating occurs more near the middle troposphere. Below the dust layer, the atmosphere may experience cooling because of adiabatic ascent forced by the heating above or by reduced solar absorption near the top of the boundary layer. In regions where air is relatively dry and no significant cloud-induced semi-direct effect occurs to weaken the cooling (the eastern MCR), this cooling could remove inhibition, although convection may not develop at all if it is too dry. In regions with greater relative humidity above the boundary layer (the western MCR), the cooling might be obscured due to the cloudinduced semi-direct effect.

According to our hypothesis, along with temperature and CIN changes, elevated dust-induced TC intensification in the eastern MCR and suppression in both the eastern and western MCR would occur under certain conditions, especially if the atmosphere were in a neutrally stable condition such that a little perturbation would change the direction. For the elevated dust-induced TC intensification in the eastern MCR, however, strict conditions are required as the two key factors are contradictory: no significant cloud-induced heating 
(a) AOD (RE_ON) and thermodynamic differences (RE_ON - RE_OFF)
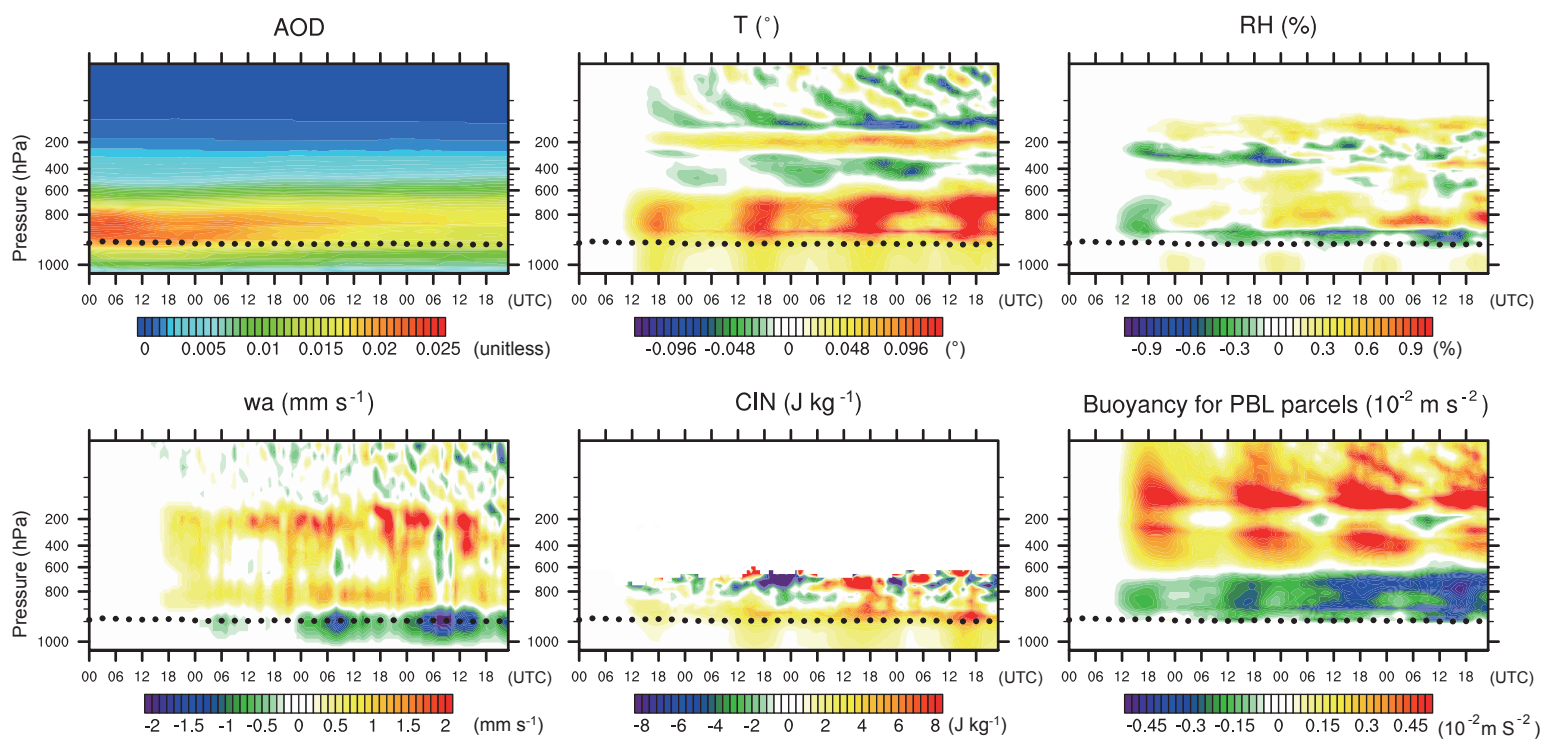

(b) Mixing ratios of clouds (liquid plus ice water) $\left(\mathrm{mg} \mathrm{kg}^{-1}\right)$

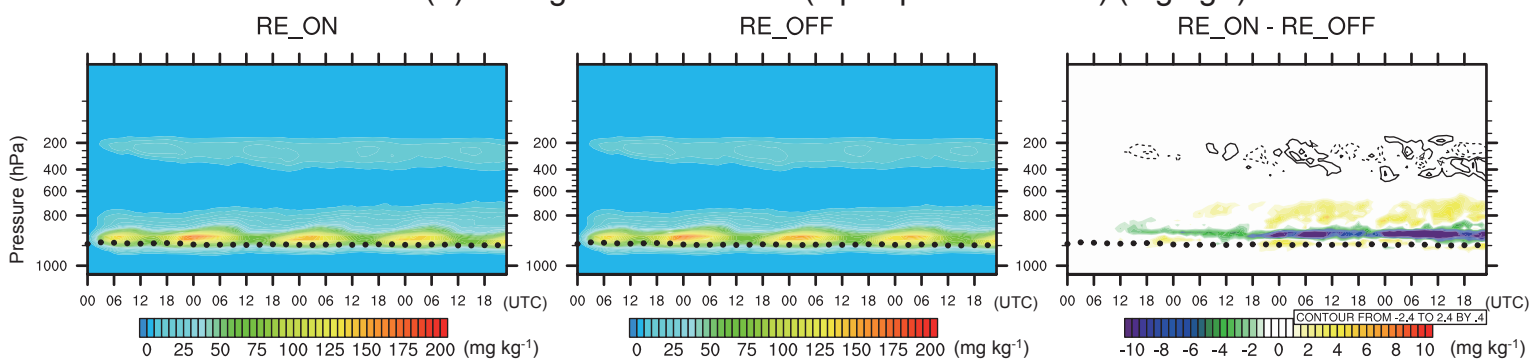

(c) The differences (RE_ON - RE_OFF) of heating rates $\left(\mathrm{K}_{\text {day }}{ }^{-1}\right)$

LW

SW

$\mathrm{LW}+\mathrm{SW}$

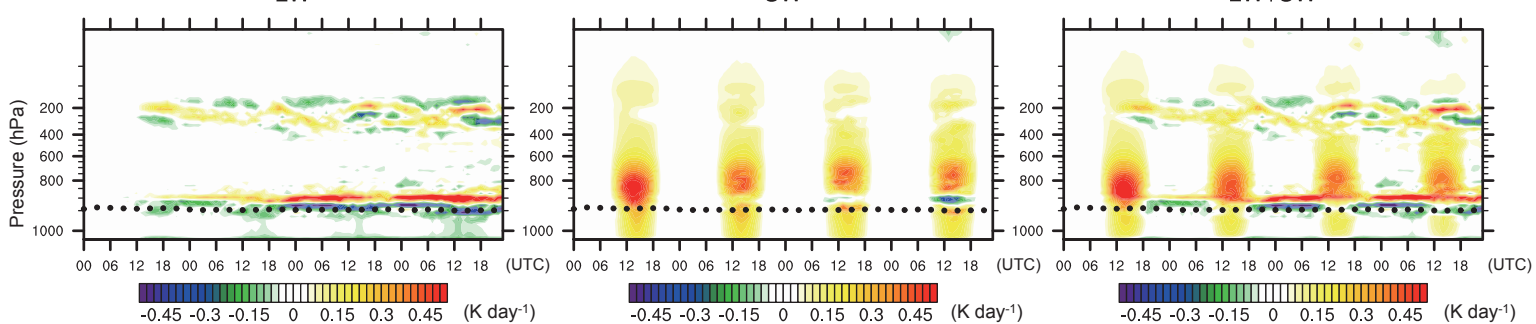

Figure 9.

requires that the air is relatively dry, while TC development requires enough moisture for convection. For the suppression cases, the possibilities in the western MCR might be larger than in the eastern MCR, since the vertical velocity decreases significantly (Figs. 7 and 9) in the western MCR, which works in the same direction as the CIN increase at the top of the boundary layer. In addition, we need to keep in mind that instability in moist convection is necessary but not sufficient for the occurrence of organized convective complexes. CIN changes by the temperature anomalies at the top of the boundary layer might be the earliest signal but not the only factor that leads to the intensification or suppression occurrence.

\subsubsection{TC case}

To interpret the dust radiative effects on TC development, we choose a case where there is a clear difference in behavior between forecasts with the dust radiative feedback operating and the feedback turned off. We view the effects of dust on the thermodynamics and the occurrence of deep, moist convection within the vortex. Microphysical effects of 
(d) Statistics at $36 \mathrm{~h}$ forecast
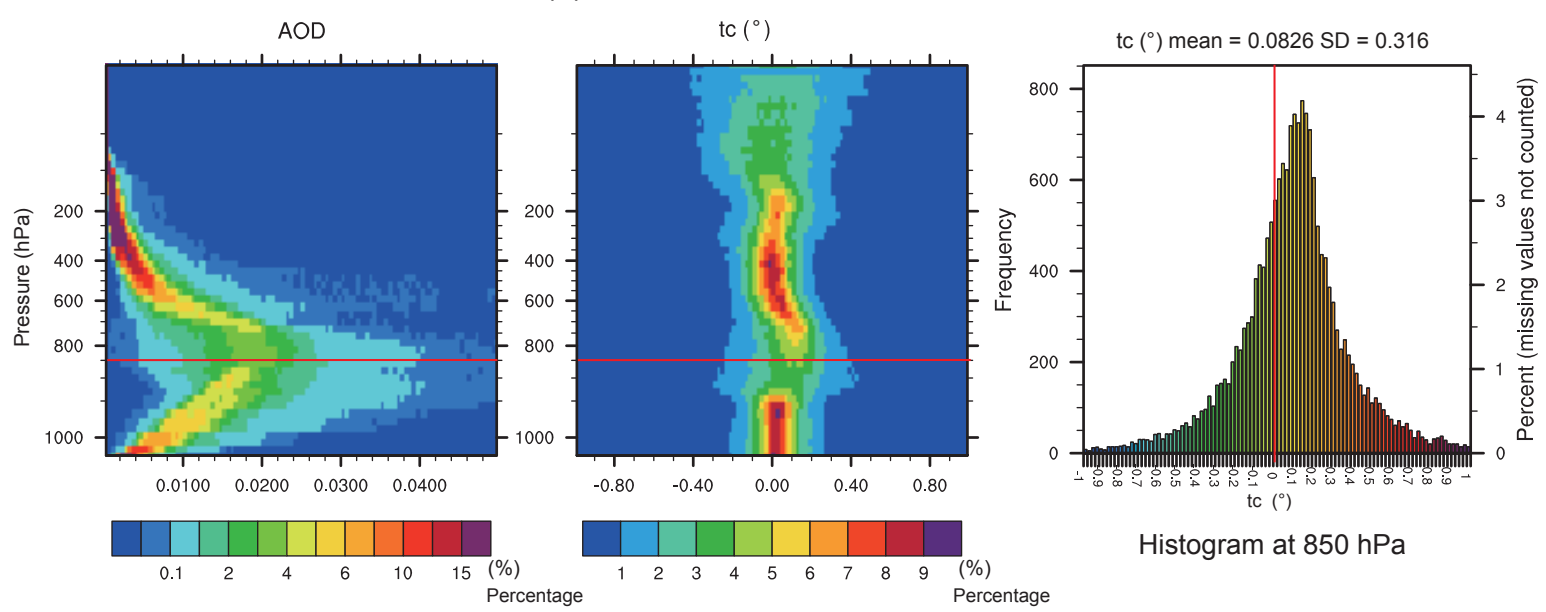

Histogram at $850 \mathrm{hPa}$

(e) Temperature tendency differences (RE_ON - RE_OFF) from five contributions ( $\mathrm{K}$ day $^{-1}$ )
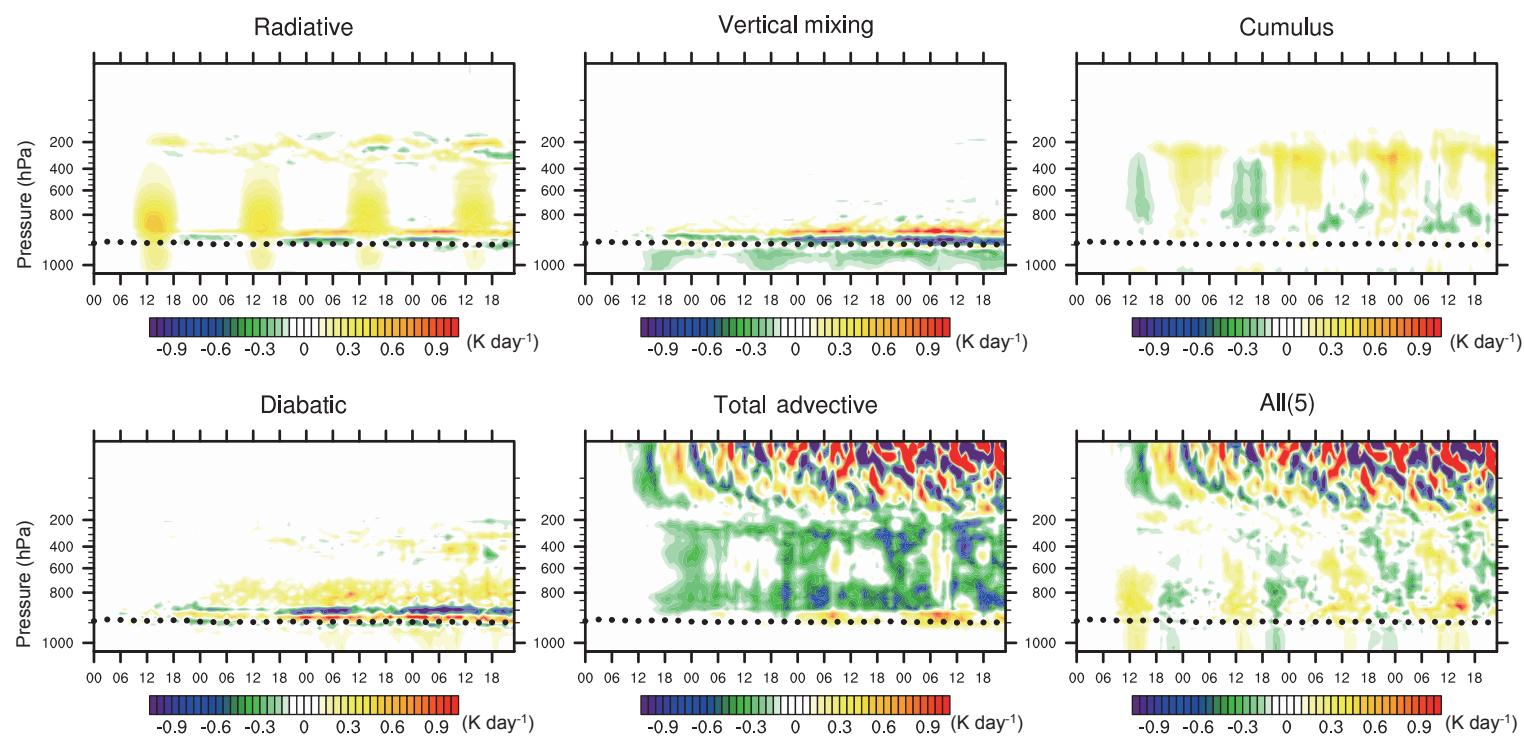

Figure 9. Same as Fig. 6, but for the "deep layer of dust" in the western MCR.

dust within the convection itself are not included. Here, the 5 September forecast is used to illustrate a case of suppressed development when dust radiative forcing is active. There was no TC in the real atmosphere on this date in the location examined here. The vortex developed within a region of cyclonic shear vorticity to the east of Hurricane Florence.

Figure 10 clearly shows the suppression of the vortex development that occurred between 72 and $90 \mathrm{~h}$ ( 8 September). The TC suppression case occurred during the $72-90 \mathrm{~h}$ forecasts initialized from 00:00 UTC on 5 September. The surface wind was almost the same at 00:00 UTC on 8 September in RE_ON and RE_OFF, but it weakened significantly in RE_ON starting from 06:00 UTC, and the differences were most prominent at 18:00 UTC. This case is also the same one as in Sun et al. (2009). The cyclone centers were tracked by GFDL vortex tracker. Figure 11 shows the cyclone-areaaveraged (defined as red rectangles in Fig. 10) AOD and differences (RE_ON - RE_OFF) for $T, \mathrm{RH}, W, \mathrm{CIN}$, and buoyancy (for boundary layer parcels) as a function of height and forecast valid time. The time series start from 00:00 UTC on 5 September. Figure 11 clearly shows the heating due to dust at $800-900 \mathrm{hPa}$ and also the CIN increase/buoyancy decrease above the PBL (black dots) in the first $72 \mathrm{~h}$ forecast, ahead of the suppression.

Figure 12 depicts the west-east cross sections across the center of MCS (red dot in Fig. 10) at 06:00 UTC on 8 September when different surface wind pattern started to show in RE_ON. Figure $12 \mathrm{a}-\mathrm{b}$ are the $(u, 100 \times w)$ streamlines and temperatures from RE_ON and RE_OFF respectively. Figure $12 \mathrm{c}-\mathrm{d}$ are the differences of temperatures 

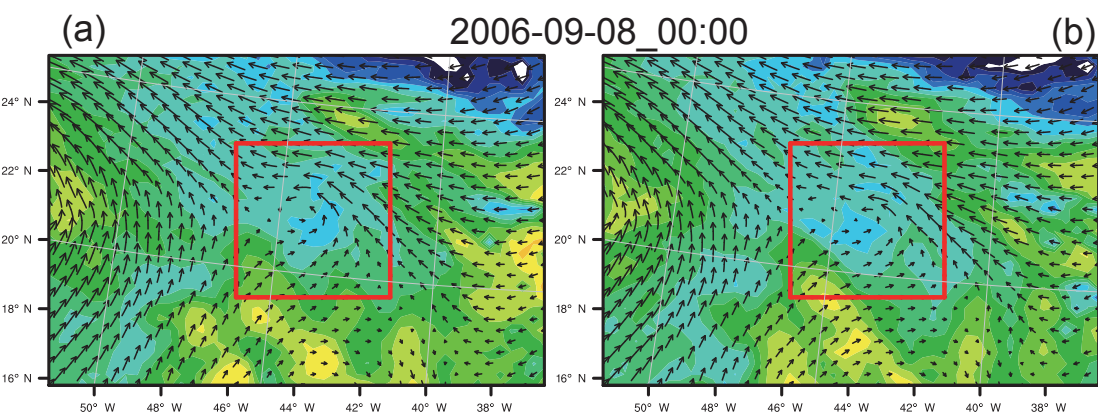

(b)
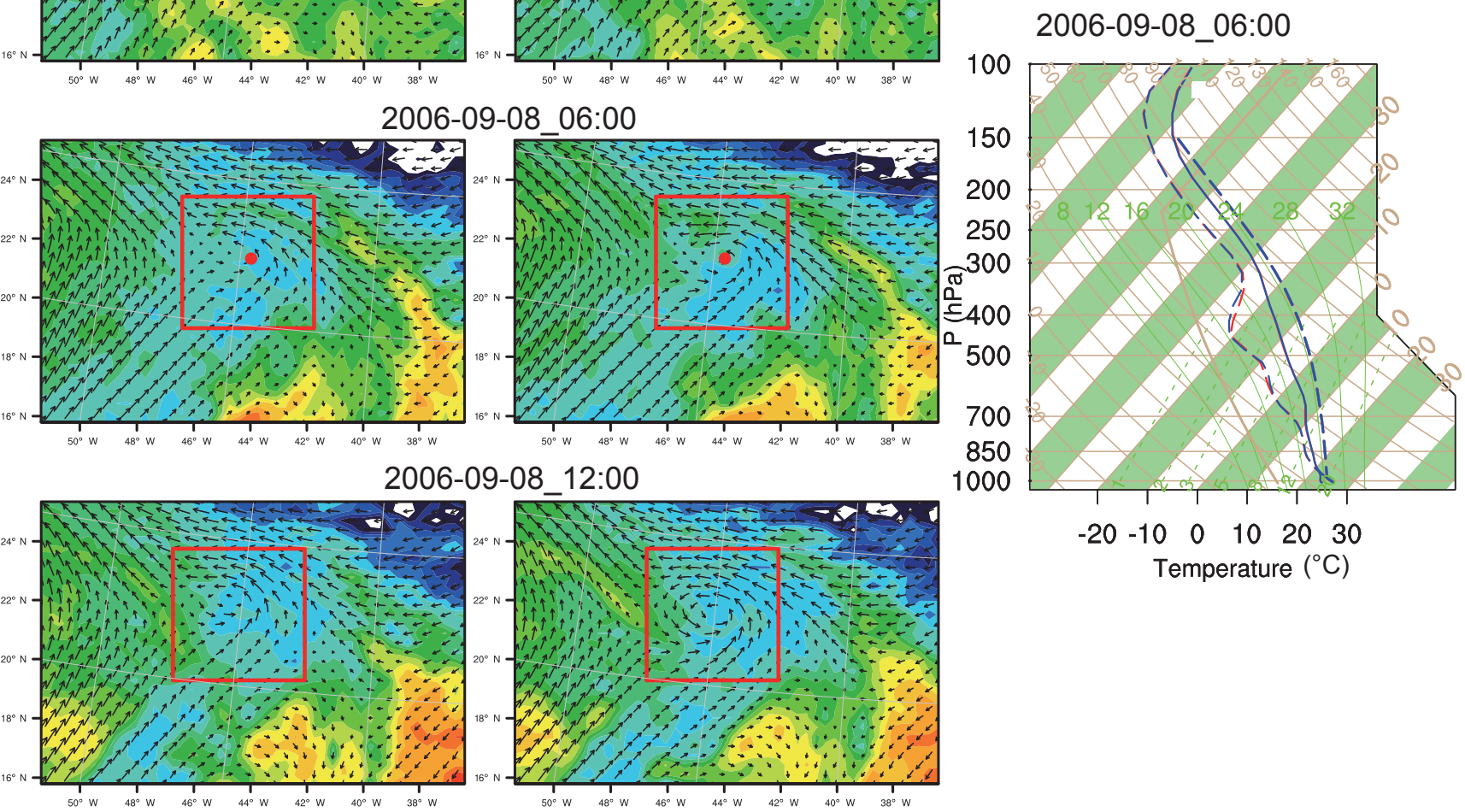

Temperature $\left({ }^{\circ} \mathrm{C}\right)$
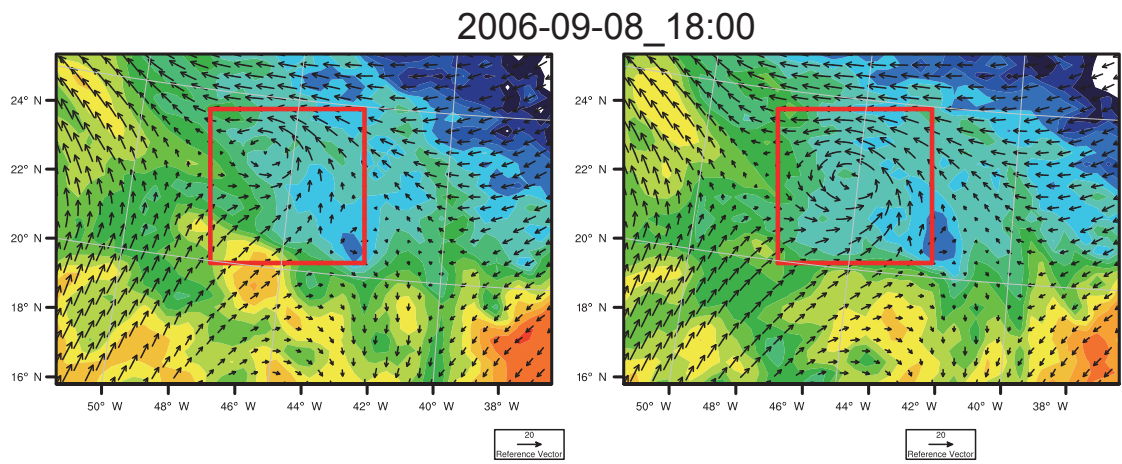

298.5299299 .5300300 .5301301 .5302302 .5303303 .5304304 .5305305 .5306306 .5307307 .5308

Potential temperatures at $900 \mathrm{hPa}(\mathrm{K})$

Figure 10. Aerosol-induced 5 September suppression case of TCs. The four rows are $10 \mathrm{~m} u-v$ wind vectors overlaid with potential temperatures at $900 \mathrm{hPa}$ for RE_ON (left) and RE_OFF (right) at the forecast time. The red rectangles and the red dot are the GFDL vortex-tracked cyclone regions and cyclone/disturbance centers respectively. The right panel is the skew $-T / \log -P$ diagram for the cyclone region average (red: RE_ON, blue: RE_OFF). The three groups of lines from left to right are dew point, temperature, and the air parcel lifted respectively. 
(a) AOD

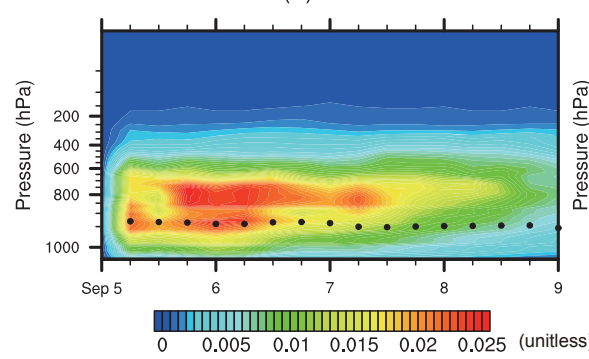

(d) $\mathrm{W}\left(\mathrm{mm} \mathrm{s}^{-1}\right)$

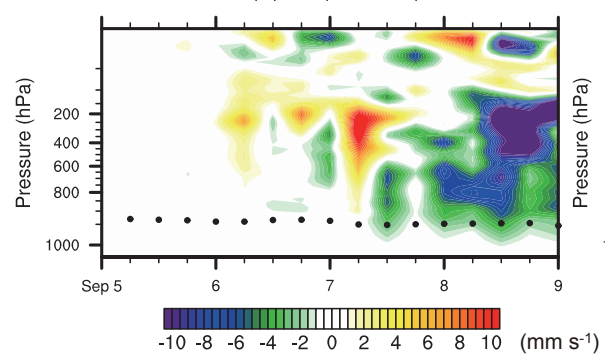

(b) $\mathrm{T}\left({ }^{\circ}\right)$

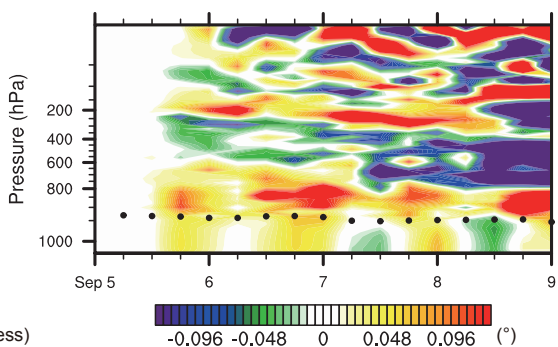

(e) $\operatorname{CIN}\left(\mathrm{J} \mathrm{kg}^{-1}\right)$

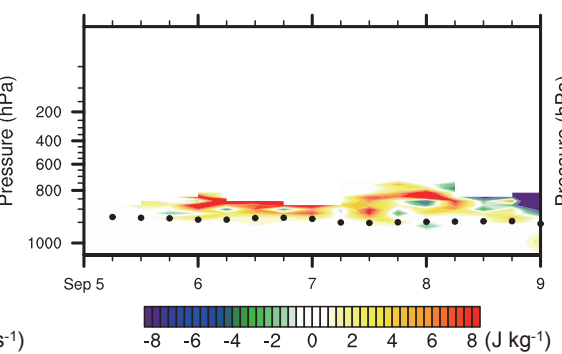

(c) $\mathrm{RH}(\%)$

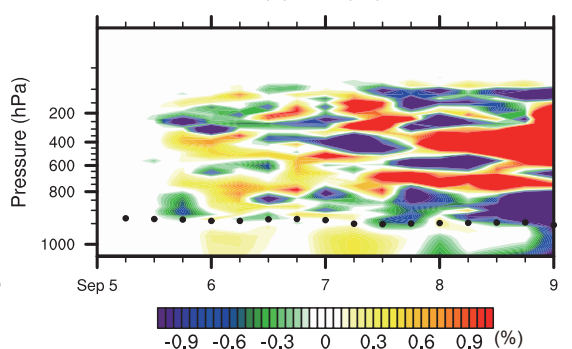

(f) Buoyancy for PBL parcels $\left(10^{-2} \mathrm{~m} \mathrm{~s}^{-2}\right)$

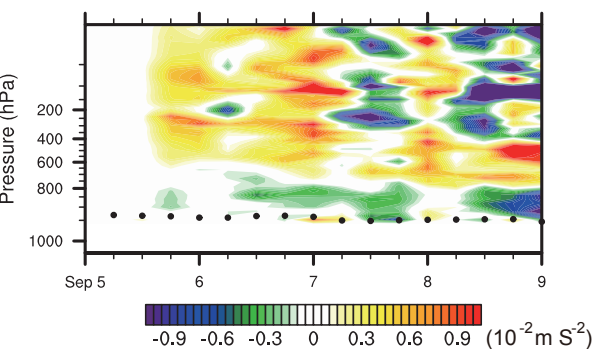

Figure 11. Tracked-cyclone-area-averaged parameters (as a function of height and time) from two experiments for the forecast initiated from 00:00 UTC on 5 September: (a) AOD from RE_ON and differences (RE_ON - RE_OFF) for (b) temperature $\left({ }^{\circ}\right)$, (c) relative humidity $(\%)$, (d) vertical velocity $\left(\mathrm{mm} \mathrm{s}^{-1}\right)$, (e) CIN $\left(\mathrm{J} \mathrm{kg}^{-1}\right)$, and (f) buoyancy for boundary layer parcels $\left(10^{-2} \mathrm{~m} \mathrm{~s}^{-2}\right)$. The cyclone area is tracked by GFDL vortex tracker and shown as the red rectangles in Fig. 10. Black dots indicate the top of the boundary layer.

and RH between the two forecasts (RE_ON-RE_OFF). Figure 12c shows different circulation patterns with weakened upward motion in RE_ON around the center of MCS at $\sim 44.6^{\circ} \mathrm{W}$ (Fig. 10). Consistent with Sun et al. (2009), the lack of upward motion weakened the large-scale boundary layer convergence which drives the deep and moist convection. Over time, these processes resulted in the erosion of the MCS. The above phenomena are very consistent with our hypothesis and also the statistic about the deep layer of dust in the western MCR: heating-induced CIN increase is the earliest signal and weakened upward motion/strengthened downward motion are the accompany results.

Figure 13 show the clouds and heating rate changes for the cyclone region. The largest AOD due to dust outbreak occurred at $600-950 \mathrm{hPa}$ for the first 2 days (Fig. 11). The low clouds were mostly at $850-950 \mathrm{hPa}$, thus the low clouds were mostly embedded in the dust layers for the first 2 days. As the longwave radiation of dust is not hooked up in the model, it can be seen that in the very beginning (during the daytime of 5 September) the dust-radiation interaction was mostly through the direct effect of shortwave absorption (Fig. 13e) around the dust maximum that reduced the amount of low clouds slightly (Fig. 13c). The changes of cloud distribution (also including the high clouds) were associated with the longwave radiation changes, which consequently caused obvious cloud changes starting from 7 September. When cloud decreases, less heating at the cloud base (cooling effect) and less cooling at the cloud top (warming effect) should be ex- pected. Although clouds started to change significantly from 7 September, it is still difficult to interpret the relationships with other factors (e.g., convection, vertical motion) that are associated with limited predictability.

\section{Conclusions}

In this study, the WRF-Chem model coupled with an AOD DA system was used to investigate the dust radiative effects on atmospheric thermodynamics and tropical cyclogenesis over the Atlantic Ocean during the summer period of 2006 (8 July-18 September). A 6-hourly analysis/forecast cycling experiment with the assimilation of MODIS $550 \mathrm{~nm}$ AOD was conducted from 00:00 UTC on 1 July to 00:00 UTC on 18 September. Comparisons with OMI show that the system depicts the dust outbreak and transport with acceptable accuracy. The dust outbreak and transport features are also consistent with the AERONET and CALIPSO observations in terms of AOD. The $180 \mathrm{~h}$ forecasts were then initialized from 00:00 UTC of each day (8 July-18 September) with the same meteorological ICs interpolated from the GFS analysis but with aerosol radiative effects active (RE_ON) and inactive (RE_OFF). Statistics of dust-induced thermodynamic changes were conducted based on the differences of the first $96 \mathrm{~h}$ forecasts of the two simulations. Four types of dust - "elevated dust"/“deep layer of dust" in the eastern MCR/western MCR were categorized and investigated 


\section{W-E across $22.3^{\circ} \mathrm{N}-44.6^{\circ} \mathrm{E}\left(2006-09-08 \_06: 00: 00\right)$}

(a)

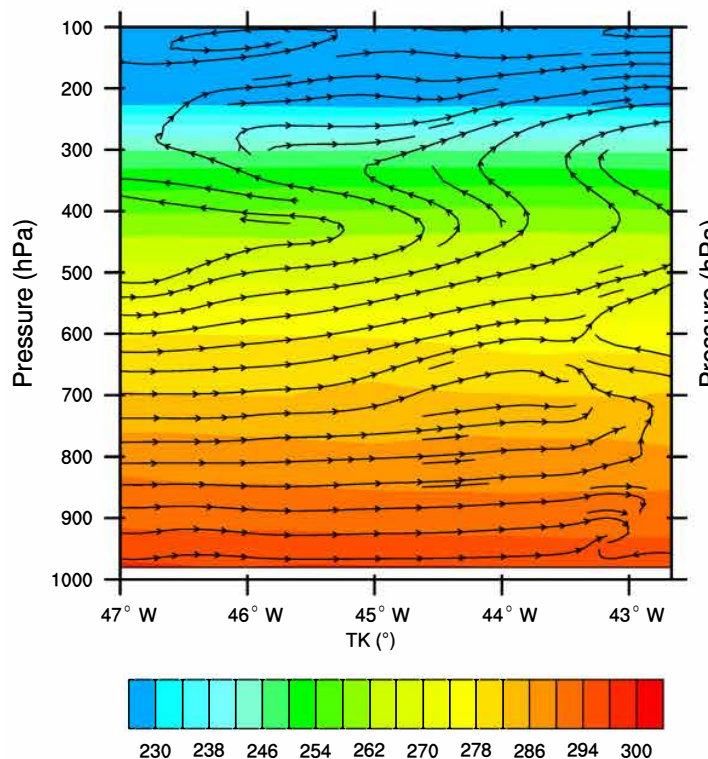

(c)

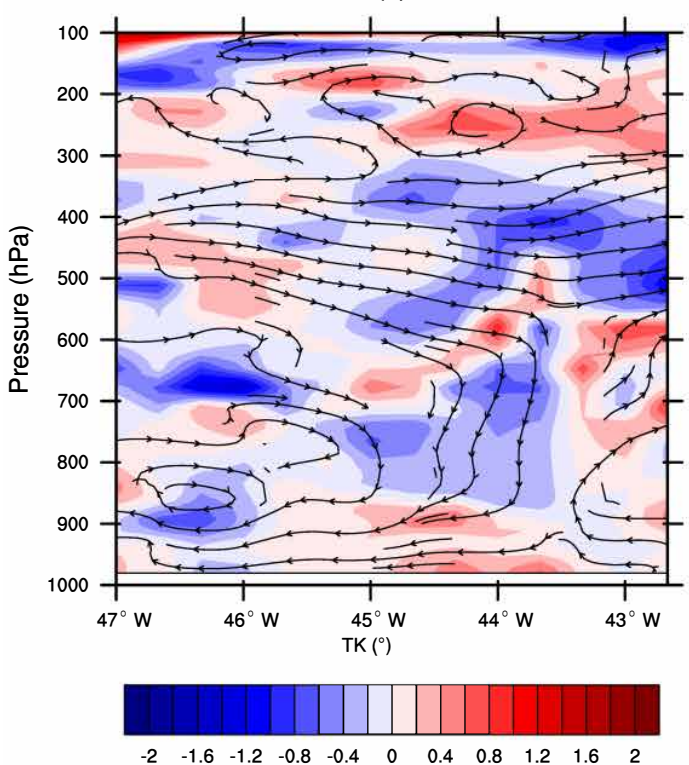

(b)

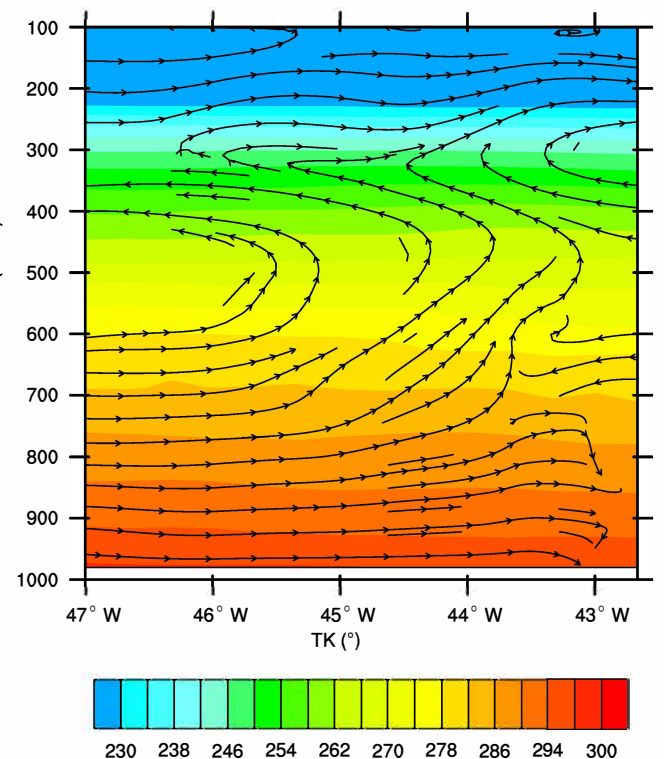

(d)

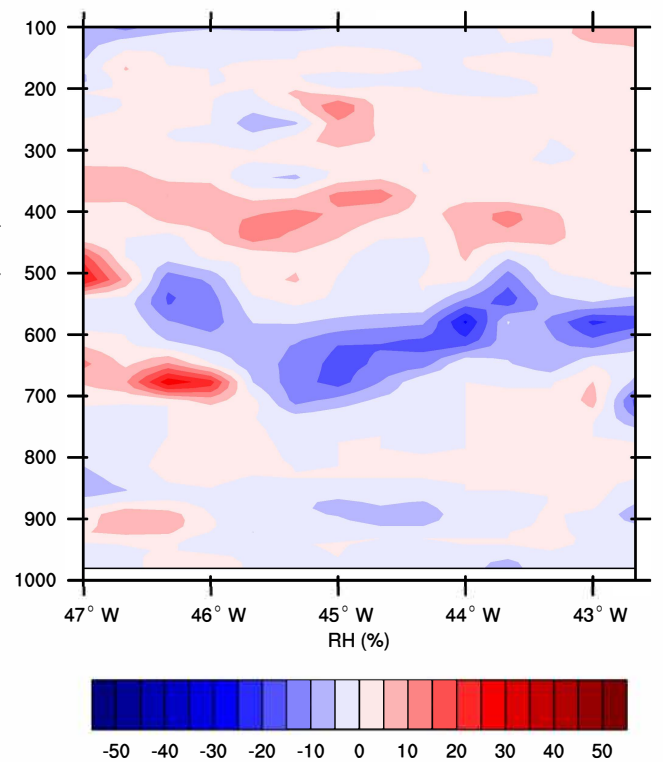

Figure 12. West-east cross sections of the cycle area (along the red center in Fig. 10) of $(u, 100 \times W)$ streamlines and temperatures from the (a) RE_ON and (b) RE_OFF experiments as well as (c) the corresponding differences (RE_ON - RE_OFF). Panel (d) is the relative humidity difference of RE_ON minus RE_OFF. The two experiments are for the $78 \mathrm{~h}$ forecast valid at 06:00 UTC on 8 September (initiated from 00:00 UTC on 5 September). The suppressed disturbance center was at $44.6^{\circ} \mathrm{W}$.

to understand the effects of dust vertical distribution and the distance to dust source region.

Statistical analysis shows that the altitude of the dust caused different thermodynamic changes especially for temperature at the top of the boundary layer, which resulted from the combination of three different processes: (1) direct radia- tive heating of dust within the dust layer, (2) adiabatic ascent (and cooling) beneath a sufficiently elevated dust layer, and (3) changes in low clouds (and associated radiative effects) that result from dust-induced thermodynamic changes. The last process is sensitive to the position of the dust layer relative to clouds and also to the cloud amount. The combina- 

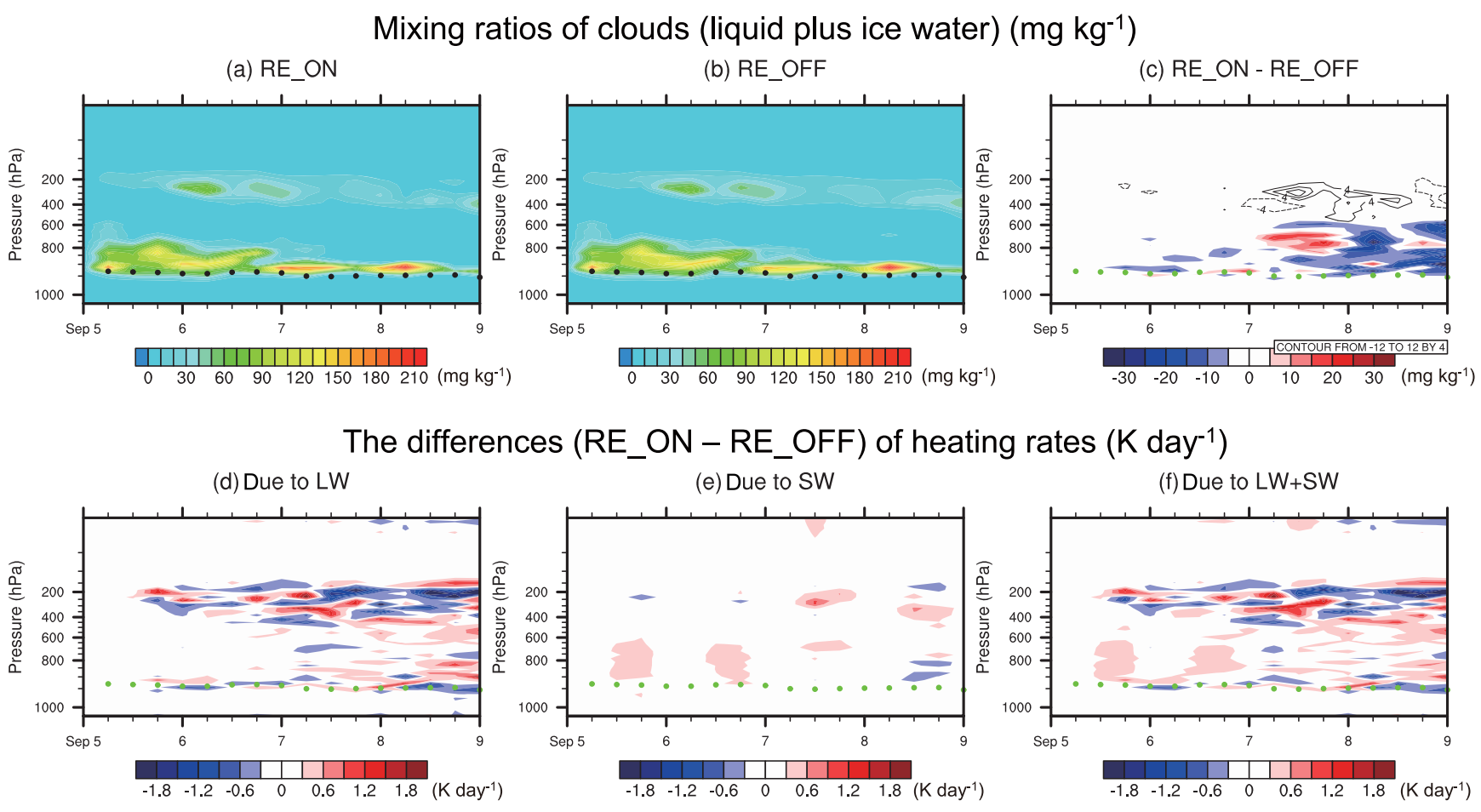

Figure 13. Same as Fig. 11, but for different parameters. Panels (a) and (b) are mixing ratios of clouds (liquid plus ice water; $\mathrm{mg} \mathrm{kg}^{-1}$ ) from RE_ON and RE_OFF respectively; (c) RE_ON - RE_OFF differences of liquid clouds (shaded) and ice clouds (contour lines, negative values in dash lines); (d-f) the differences in heating rate $\left(\mathrm{Kday}^{-1}\right)$ due to $\mathrm{LW}(\mathbf{d}), \mathrm{SW}(\mathbf{e})$ and LW $+\mathrm{SW}$ (f) radiative effects respectively. Black/green dots indicate the top of the boundary layer.

tion of these processes caused different temperature changes for different cases at the top of the boundary layer: (a) significant cooling for the cases of elevated dust in the eastern MCR (near-desert region where air is dry) by combined processes 1 and 2, (b) slight warming for elevated dust in the western MCR by the three processes (where cloud-induced heating offsets adiabatic cooling), and (c) significant warming for deep layers of dust in both regions by processes 1 and 3. The statistics showed the temperature anomalies occur as early as in the first 1-2 days, then become prominent during the 2nd-3rd day, and remain consistent to the end of the $96 \mathrm{~h}$ forecast; the only exception is for the deep layer of dust in the eastern MCR where the later forecasts (after $48 \mathrm{~h}$ ) showed much more complicated thermodynamic responses that result from changes in deep convection.

As CIN is sensitive to the temperature just above the boundary layer, we assume that dust-induced temperature changes may modulate convection frequency and intensity. For suppression cases, heating near or above the top of the boundary layer leads to a CIN increase and buoyancy decrease for boundary layer parcels, thereby suppressing convection. However, it should be noted that heating within the boundary layer itself, due to dust, can increase convective available potential energy by increasing parcel temperatures and buoyancy. This would offset the warming near and above the top of the PBL. The possibility for suppression to occur in the western MCR is larger than in the eastern MCR, as the statistics show decreased vertical velocities in the western MCR that contribute to an increase of convective inhibition. While destabilization due to elevated dust is possible in the eastern MCR, it requires more strict conditions so that the moisture in the air is in a range that does not cause too much clouds and heating rate changes but meanwhile provides enough energy for convection development - which might be contradictory in reality.

The 5 September TC suppression case proved our hypothesis on the deep layer of dust. The case study also revealed that weakened upward (strengthened downward) motions and cloud-induced semi-direct effects were also found at the same time when the suppression occurred. It should be noted that although the simulations are for the 2.5 months (8 July-18 September 2006), the samples of the TC suppression are limited. We only selected one suppression case which might not be typical enough. More investigations are needed to better understand these complex interactions so as to further evaluate our hypothesis.

Data availability. Data used in this publication can be accessed by contacting the authors Zhiquan Liu (liuz@ucar.edu) and Dan Chen (dchen@ucar.edu). 
Competing interests. The authors declare that they have no conflict of interest.

Acknowledgements. This work is partially supported by grants from the US Air Force Weather Agency. The authors thank Wei Wang for help with the thermodynamic budget issue, Junmei Ban for help with the AERONET graphs and Hailing Zhang for help with the GFDL vortex tracker package. The authors also thank Jin Feng for his helpful discussions on the gravity wave issue. NCAR is sponsored by the National Science Foundation.

Edited by: Christopher Hoyle

Reviewed by: two anonymous referees

\section{References}

Ackerman, A. S., Toon, O. B., Stevens, D. E., Heymsfield, A. J., Ramanathan, V., and Welton, E. J.: Reduction of tropical cloudiness by soot, Science, 288, 1042-1047, https://doi.org/10.1126/science.288.5468.1042, 2000.

Ahn, C., Torres, O., and Jethva, H.: Assessment of OMI near-UV aerosol optical depth over land, J. Geophys. Res.-Atmos., 119, 2457-2473, https://doi.org/10.1002/2013jd020188, 2014.

Barnard, J. C., Fast, J. D., Paredes-Miranda, G., Arnott, W. P., and Laskin, A.: Technical Note: Evaluation of the WRF-Chem "Aerosol Chemical to Aerosol Optical Properties" Module using data from the MILAGRO campaign, Atmos. Chem. Phys., 10, 7325-7340, https://doi.org/10.5194/acp-10-7325-2010, 2010.

Bretl, S., Reutter, P., Raible, C. C., Ferrachat, S., Poberaj, C. S., Revell, L. E., and Lohmann, U.: The influence of absorbed solar radiation by Saharan dust on hurricane genesis, J. Geophys. Res.Atmos., 120, 1902-1917, https://doi.org/10.1002/2014jd022441, 2015.

Carlson, T. N. and Benjamin, S. G.: Radiative Heating Rates for Saharan Dust, J. Atmos. Sci., $\quad 37, \quad 193-213, \quad$ https://doi.org/10.1175/15200469(1980)037<0193:Rhrfsd>2.0.Co;2, 1980.

Chen, D., Liu, Z., Schwartz, C. S., Lin, H.-C., Cetola, J. D., Gu, Y., and Xue, L.: The impact of aerosol optical depth assimilation on aerosol forecasts and radiative effects during a wild fire event over the United States, Geosci. Model Dev., 7, 2709-2715, https://doi.org/10.5194/gmd-7-2709-2014, 2014.

Chen, S. H., Wang, S. H., and Waylonis, M.: Modification of Saharan air layer and environmental shear over the eastern Atlantic Ocean by dust-radiation effects, J. Geophys. Res.-Atmos., 115, D21202, https://doi.org/10.1029/2010jd014158, 2010.

Chin, M., Savoie, D. L., Huebert, B. J., Bandy, A. R., Thornton, D. C., Bates, T. S., Quinn, P. K., Saltzman, E. S., and De Bruyn, W. J.: Atmospheric sulfur cycle simulated in the global model GOCART: Comparison with field observations and regional budgets, J. Geophys. Res.-Atmos., 105, 24689-24712, https://doi.org/10.1029/2000jd900385, 2000.

Chin, M., Ginoux, P., Kinne, S., Torres, O., Holben, B. N., Duncan, B. N., Martin, R. V., Logan, J. A., Higurashi, A., and Nakajima, T.: Tropospheric aerosol optical thickness from the GOCART model and comparisons with satellite and Sun photometer measurements,
J. Atmos. Sci., 59, 461-483, https://doi.org/10.1175/15200469(2002)059<0461:Taotft>2.0.Co;2, 2002.

Choobari, O. A., Zawar-Reza, P., and Sturman, A.: The global distribution of mineral dust and its impacts on the climate system: A review, Atmos. Res., 138, 152-165, https://doi.org/10.1016/j.atmosres.2013.11.007, 2014.

Chou, M.-D. and Suarez, M. J.: An efficient thermal infrared radiation parameterization for use in general circulation models, NASA Tech. Memo., TM 104606, vol. 3, 25 pp., NASA Goddard Space Flight Cent., Greenbelt, Md., USA, 1994.

Collins, W. D., Rasch, P. J., Eaton, B. E., Khattatov, B. V., Lamarque, J. F., and Zender, C. S.: Simulating aerosols using a chemical transport model with assimilation of satellite aerosol retrievals: Methodology for INDOEX, J. Geophys. Res.-Atmos., 106, 7313-7336, https://doi.org/10.1029/2000jd900507, 2001.

Cook, J. and Highwood, E. J.: Climate response to tropospheric absorbing aerosols in an intermediate generalcirculation model, Q. J. Roy. Meteor. Soc., 130, 175-191, https://doi.org/10.1256/qj.03.64, 2004.

Dunion, J. P. and Velden, C. S.: The impact of the Saharan air layer on Atlantic tropical cyclone activity, B. Am. Meteorol. Soc., 85, 353-365, https://doi.org/10.1175/Bams-85-3-353, 2004.

Eck, T. F., Holben, B. N., Reid, J. S., Dubovik, O., Smirnov, A., O’Neill, N. T., Slutsker, I., and Kinne, S.: Wavelength dependence of the optical depth of biomass burning, urban, and desert dust aerosols, J. Geophys. Res.-Atmos., 104, 31333 31349, https://doi.org/10.1029/1999jd900923, 1999.

Evan, A. T., Dunion, J., Foley, J. A., Heidinger, A. K., and Velden, C. S.: New evidence for a relationship between Atlantic tropical cyclone activity and African dust outbreaks, Geophys. Res. Lett., 33, L19813, https://doi.org/10.1029/2006gl026408, 2006.

$\mathrm{Fu}, \mathrm{Q}$. and Liou, K. N.: Parameterization of the Radiative Properties of Cirrus Clouds, J. Atmos. Sci., 50, 2008-2025, https://doi.org/10.1175/1520 0469(1993)050<2008:Potrpo>2.0.Co;2, 1993.

Ginoux, P., Chin, M., Tegen, I., Prospero, J. M., Holben, B., Dubovik, O., and Lin, S. J.: Sources and distributions of dust aerosols simulated with the GOCART model, J. Geophys. Res.-Atmos., 106, 20255-20273, https://doi.org/10.1029/2000jd000053, 2001.

Grassl, H.: Albedo Reduction and Radiative Heating of Clouds by Absorbing Aerosol Particles, Contrib. Atmos. Phys., 48, 199210,1975 .

Grell, G. A. and Devenyi, D.: A generalized approach to parameterizing convection combining ensemble and data assimilation techniques, Geophys. Res. Lett., 29, 1693, https://doi.org/10.1029/2002gl015311, 2002.

Grell, G. A., Peckham, S. E., Schmitz, R., McKeen, S. A., Frost, G., Skamarock, W. C., and Eder, B.: Fully coupled "online" chemistry within the WRF model, Atmos. Environ., 39, 6957-6975, https://doi.org/10.1016/j.atmosenv.2005.04.027, 2005.

Gu, Y., Liou, K. N., Chen, W., and Liao, H.: Direct climate effect of black carbon in China and its impact on dust storms, J. Geophys. Res.-Atmos., 115, D00k14, https://doi.org/10.1029/2009jd013427, 2010.

Gu, Y., Xue, Y., De Sales, F., and Liou, K. N.: A GCM investigation of dust aerosol impact on the regional climate of North Africa and South/East Asia, Clim. Dynam., 46, 2353-2370, https://doi.org/10.1007/s00382-015-2706-y, 2016. 
Han, Y., van Delst, P., Liu, Q., Weng, F., Yan, B., Treadon, R., and Derber, J.: JCSDA Community Radiative Transfer Model (CRTM) - Version 1, NOAA Tech. Rep. NESDIS 122, 33 pp., NOAA Silver Spring, Md., USA, 2006.

Hansen, J., Sato, M., and Ruedy, R.: Radiative forcing and climate response, J. Geophys. Res.-Atmos., 102, 6831-6864, https://doi.org/10.1029/96jd03436, 1997.

Hazra, A., Mukhopadhyay, P., Taraphdar, S., Chen, J. P., and Cotton, W. R.: Impact of aerosols on tropical cyclones: An investigation using convection-permitting model simulation, J. Geophys. Res.Atmos., 118, 7157-7168, https://doi.org/10.1002/jgrd.50546, 2013.

Hsu, N. C., Tsay, S. C., King, M. D., and Herman, J. R.: Aerosol properties over bright-reflecting source regions, IEEE T. Geosci. Remote., 42, 557-569, https://doi.org/10.1109/Tgrs.2004.824067, 2004.

Jenkins, G. S., Pratt, A. S., and Heymsfield, A.: Possible linkages between Saharan dust and tropical cyclone rain band invigoration in the eastern Atlantic during NAMMA-06, Geophys. Res. Lett., 35, L08815, https://doi.org/10.1029/2008g1034072, 2008.

Johnson, B. T., Shine, K. P., and Forster, P. M.: The semidirect aerosol effect: Impact of absorbing aerosols on marine stratocumulus, Q. J. Roy. Meteor. Soc., 130, 1407-1422, https://doi.org/10.1256/qj.03.61, 2004.

Jones, T. A., Cecil, D. J., and Dunion, J.: The environmental and inner-core conditions governing the intensity of Hurricane Erin (2001), Weather Forecast., 22, 708-725, https://doi.org/10.1175/Waf1017.1, 2007.

Karyampudi, V. M. and Carlson, T. N.: Analysis and Numerical Simulations of the Saharan Air Layer and Its Effect on Easterly Wave Disturbances, J. Atmos. Sci., 45, 3102-3136, https://doi.org/10.1175/15200469(1988)045<3102:Aansot>2.0.Co;2, 1988.

Karyampudi, V. M. and Pierce, H. F.: Synoptic-scale influence of the Saharan air layer on tropical cyclogenesis over the eastern Atlantic, Mon. Weather Rev., 130, 3100-3128, https://doi.org/10.1175/15200493(2002)130<3100:Ssiots>2.0.Co;2, 2002.

Kaufman, Y. J. and Koren, I.: Smoke and pollution aerosol effect on cloud cover, Science, 313, 655-658, https://doi.org/10.1126/science.1126232, 2006.

Koch, D. and Del Genio, A. D.: Black carbon semi-direct effects on cloud cover: review and synthesis, Atmos. Chem. Phys., 10, 7685-7696, https://doi.org/10.5194/acp-10-7685-2010, 2010.

Koren, I., Kaufman, Y. J., Rosenfeld, D., Remer, L. A., and Rudich, Y.: Aerosol invigoration and restructuring of Atlantic convective clouds, Geophys. Res. Lett., 32, L14828, https://doi.org/10.1029/2005g1023187, 2005.

Koren, I., Martins, J. V., Remer, L. A., and Afargan, H.: Smoke invigoration versus inhibition of clouds over the Amazon, Science, 321, 946-949, https://doi.org/10.1126/science.1159185, 2008.

Landsea, C. W.: A Climatology of Intense (or Major) Atlantic Hurricanes, Mon. Weather Rev., 121, 1703-1713, https://doi.org/10.1175/15200493(1993)121<1703:Acoima>2.0.Co;2, 1993.

Lau, K. M., Kim, M. K., and Kim, K. M.: Asian summer monsoon anomalies induced by aerosol direct forcing: the role of the Tibetan Plateau, Clim. Dynam., 26, 855-864, https://doi.org/10.1007/s00382-006-0114-z, 2006.
Lau, K. M., Kim, K. M., Sud, Y. C., and Walker, G. K.: A GCM study of the response of the atmospheric water cycle of West Africa and the Atlantic to Saharan dust radiative forcing, Ann. Geophys., 27, 4023-4037, https://doi.org/10.5194/angeo27-4023-2009, 2009.

Liu, Q. H. and Weng, F. Z.: Advanced doubling-adding method for radiative transfer in planetary atmospheres, J. Atmos. Sci., 63, 3459-3465, https://doi.org/10.1175/Jas3808.1, 2006.

Liu, Z. Q., Liu, Q. H., Lin, H. C., Schwartz, C. S., Lee, Y. H., and Wang, T. J.: Three-dimensional variational assimilation of MODIS aerosol optical depth: Implementation and application to a dust storm over East Asia, J. Geophys. Res.-Atmos., 116, D23206, https://doi.org/10.1029/2011jd016159, 2011.

Lohmann, U. and Feichter, J.: Can the direct and semidirect aerosol effect compete with the indirect effect on a global scale?, Geophys. Res. Lett., 28, 159-161, https://doi.org/10.1029/2000g1012051, 2001.

Parrish, D. F. and Derber, J. C.: The National-MeteorologicalCenters Spectral Statistical-Interpolation Analysis System, Mon. Weather Rev., 120, 1747-1763, https://doi.org/10.1175/15200493(1992)120<1747:Tnmcss>2.0.Co;2, 1992.

Pratt, A. S. and Evans, J. L.: Potential Impacts of the Saharan Air Layer on Numerical Model Forecasts of North Atlantic Tropical Cyclogenesis, Weather Forecast., 24, 420-435, https://doi.org/10.1175/2008waf2007090.1, 2009.

Quijano, A. L., Sokolik, I. N., and Toon, O. B.: Radiative heating rates and direct radiative forcing by mineral dust in cloudy atmospheric conditions, J. Geophys. Res.-Atmos., 105, 12207-12219, https://doi.org/10.1029/2000jd900047, 2000.

Ramanathan, V., Crutzen, P. J., Kiehl, J. T., and Rosenfeld, D.: Atmosphere - Aerosols, climate, and the hydrological cycle, Science, 294, 2119-2124, https://doi.org/10.1126/science.1064034, 2001.

Reale, O., Lau, W. K., Kim, K. M., and Brin, E.: Atlantic Tropical Cyclogenetic Processes during SOP-3 NAMMA in the GEOS-5 Global Data Assimilation and Forecast System, J. Atmos. Sci., 66, 3563-3578, https://doi.org/10.1175/2009jas3123.1, 2009.

Reale, O., Lau, K. M., da Silva, A., and Matsui, T.: Impact of assimilated and interactive aerosol on tropical cyclogenesis, Geophys. Res. Lett., 41, 3282-3288, https://doi.org/10.1002/2014gl059918, 2014.

Remer, L. A., Kaufman, Y. J., Tanre, D., Mattoo, S., Chu, D. A., Martins, J. V., Li, R. R., Ichoku, C., Levy, R. C., Kleidman, R. G., Eck, T. F., Vermote, E., and Holben, B. N.: The MODIS aerosol algorithm, products, and validation, J. Atmos. Sci., 62, 947-973, https://doi.org/10.1175/Jas3385.1, 2005.

Rosenfeld, D., Lohmann, U., Raga, G. B., O’Dowd, C. D., Kulmala, M., Fuzzi, S., Reissell, A., and Andreae, M. O.: Flood or drought: How do aerosols affect precipitation?, Science, 321, 1309-1313, https://doi.org/10.1126/science.1160606, 2008.

Schwartz, C. S., Liu, Z. Q., Lin, H. C., and Cetola, J. D.: Assimilating aerosol observations with a "hybrid" variational-ensemble data assimilation system, J. Geophys. Res.-Atmos., 119, 40434069, https://doi.org/10.1002/2013JD020937, 2014.

Shu, S. J. and Wu, L. G.: Analysis of the influence of Saharan air layer on tropical cyclone intensity using AIRS/Aqua data, Geophys. Res. Lett., 36, L09809, https://doi.org/10.1029/2009gl037634, 2009. 
Sokolik, I. N., Toon, O. B., and Bergstrom, R. W.: Modeling the radiative characteristics of airborne mineral aerosols at infrared wavelengths, J. Geophys. Res.-Atmos., 103, 8813-8826, https://doi.org/10.1029/98jd00049, 1998.

Su, J., Huang, J., Fu, Q., Minnis, P., Ge, J., and Bi, J.: Estimation of Asian dust aerosol effect on cloud radiation forcing using FuLiou radiative model and CERES measurements, Atmos. Chem. Phys., 8, 2763-2771, https://doi.org/10.5194/acp-8-2763-2008, 2008.

Sun, D. L., Lau, K. M., and Kafatos, M.: Contrasting the 2007 and 2005 hurricane seasons: Evidence of possible impacts of Saharan dry air and dust on tropical cyclone activity in the Atlantic basin, Geophys. Res. Lett., 35, L15405, https://doi.org/10.1029/2008gl034529, 2008.

Sun, D. L., Lau, W. K. M., Kafatos, M., Boybeyi, Z., Leptoukh, G., Yang, C. W., and Yang, R. X.: Numerical Simulations of the Impacts of the Saharan Air Layer on Atlantic Tropical Cyclone Development, J. Climate, 22, 6230-6250, https://doi.org/10.1175/2009jcli2738.1, 2009.

Wang, Y., Lee, K. H., Lin, Y., Levy, M., and Zhang, R. Y.: Distinct effects of anthropogenic aerosols on tropical cyclones, Nat. Clim. Change, 4, 368-373, https://doi.org/10.1038/Nclimate2144, 2014.

Winker, D. M., Vaughan, M. A., Omar, A., Hu, Y. X., Powell, K. A., Liu, Z. Y., Hunt, W. H., and Young, S. A.: Overview of the CALIPSO Mission and CALIOP Data Processing Algorithms, J. Atmos. Ocean. Tech., 26, 2310-2323, https://doi.org/10.1175/2009JTECHA1281.1, 2009.

Wong, S., Dessler, A. E., Mahowald, N. M., Yang, P., and Feng, Q.: Maintenance of Lower Tropospheric Temperature Inversion in the Saharan Air Layer by Dust and Dry Anomaly, J. Climate, 22, 5149-5162, https://doi.org/10.1175/2009jcli2847.1, 2009.
Wu, L. G.: Impact of Saharan air layer on hurricane peak intensity, Geophys. Res. Lett., 34, L09802, https://doi.org/10.1029/2007g1029564, 2007.

Wu, W. S., Purser, R. J., and Parrish, D. F.: Three-dimensional variational analysis with spatially inhomogeneous covariances, Mon. Weather Rev., 130, 2905-2916, https://doi.org/10.1175/15200493(2002)130<2905:Tdvaws>2.0.Co;2, 2002.

Yang, S., Shi, G. Y., Chen, L., Wang, B., and Yang, H. L.: Evaluation of Moderate-Resolution Imaging Spectroradiometer (MODIS) Deep Blue Aerosol Products Using Ground-Based Measurements over Beijing, Sola, 7, 133-136, https://doi.org/10.2151/sola.2011-034, 2011.

Zhang, H. N., McFarquhar, G. M., Cotton, W. R., and Deng, Y.: Direct and indirect impacts of Saharan dust acting as cloud condensation nuclei on tropical cyclone eyewall development, Geophys. Res. Lett., 36, L06802, https://doi.org/10.1029/2009g1037276, 2009.

Zhao, C., Liu, X., Leung, L. R., Johnson, B., McFarlane, S. A., Gustafson Jr., W. I., Fast, J. D., and Easter, R.: The spatial distribution of mineral dust and its shortwave radiative forcing over North Africa: modeling sensitivities to dust emissions and aerosol size treatments, Atmos. Chem. Phys., 10, 8821-8838, https://doi.org/10.5194/acp-10-8821-2010, 2010.

Zhu, A., Ramanathan, V., Li, F., and Kim, D.: Dust plumes over the Pacific, Indian, and Atlantic oceans: Climatology and radiative impact, J. Geophys. Res.-Atmos., 112, D16208, https://doi.org/10.1029/2007jd008427, 2007. 